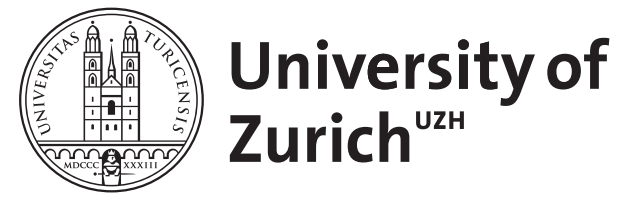

\title{
Flexible valency in Chintang
}

Schikowski, Robert ; Bickel, Balthasar ; Paudyal, Netra P

Posted at the Zurich Open Repository and Archive, University of Zurich

ZORA URL: https://doi.org/10.5167/uzh-112581

Book Section

Published Version

Originally published at:

Schikowski, Robert; Bickel, Balthasar; Paudyal, Netra P (2015). Flexible valency in Chintang. In: Malchukov, Andrej; Comrie, Bernard. Valency Classes in the World's Languages. Berlin: Mouton De Gruyter, 669-708. 


\section{Robert Schikowski, Netra Paudyal, and Balthasar Bickel 18 Flexible valency in Chintang ${ }^{1}$}

\section{The Chintang language}

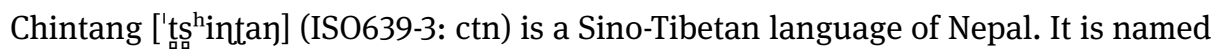
after the village where it is mainly spoken. The village lies in the hills of Eastern Nepal, bigger cities within a day's reach being Dhankuțā and Dharān.

There are no official data on the number of speakers, but we estimate there to be around 4,000-5,000 speakers. Most speakers are bi- or trilingual, with Nepali (the Indo-Aryan lingua franca of Nepal) as one and Bantawa (a related Sino-Tibetan language) as the other additional language. Monolingual speakers are still to be found mainly among elderly women, whereas a considerable portion of the younger generation is rapidly shifting to Nepali.

Genealogically, Chintang belongs to the Kiranti group. The Kiranti languages are generally accepted to belong to the large Sino-Tibetan (or Tibeto-Burman) family, although their position within this family is controversial (cf. e.g., Thurgood 2003; Ebert 2003). Based on phonological evidence, Chintang belongs to the Eastern subgroup of Kiranti (Bickel et al. 2010). There are two major dialects (Mulgaũ and Sambugaũ), named after the areas where they are spoken. The differences between them concern morphology and the lexicon but, as far as we know, not syntax, and so we will not distinguish between dialects in this chapter.

For all examples the source has been marked behind the translation. Wherever possible, we take data from the Chintang Language Corpus (Bickel et al. 2011), limiting ourselves to utterances by fully fluent adults. ${ }^{2}$

1 The research reported here was made possible by Grant No. II/79092 from the Volkswagen Foundation and Grant No. 799/5-1 from the Deutsche Forschungsgemeinschaft. Author contributions are as follows: Schikowski did the main work on the lexicon and the analysis of valency. Bickel contributed additional analyses to valency patterns and Paudyal additional analyses to the lexicon. Schikowski and Bickel wrote the paper. For more information in Chintang see http://www.clrp.uzh.ch/ clrp. All graphs in the paper were produced using R (R Development Core Team 2012), with the additional package vcd (Meyer et al. 2009).

2 We indicate data sources in brackets after translations. Source indicators beginning with CL refer to adult speech that was recorded along with child language; see Stoll et al. (2012) for general information on the recordings. 


\section{Basic morphosyntax}

\subsection{Predicates and referents}

The argument relation in Chintang is typically double-marked: referential phrases bear case suffixes (cf. $\S 2.2$ ), predicates index person, number and clusivity of one or two referents (cf. §2.3), depending on verb class. The only exception to this pattern are equational clauses without a copula, where there is no verb at all.

It is essential for the description of valency to distinguish between arguments and adjuncts. Morphosyntactic criteria are of little use for this aim since they do not yield consistent separation. For instance, bipersonal agreement, which might be taken as a morphological indicator of argumenthood, is generally variable - all verbs that can have bipersonal agreement can also have monopersonal agreement, and verbs form a continuum with respect to which type of inflection they display more frequently (an observation to which we return below). The presence of referring NPs, a popular indicator of argumenthood on the syntactic side, is even less stable: like the neighboring and closely related language Belhare (Bickel 2003), Chintang discourse tends to have extremely low referential density, i.e. for any referent, the default is not to be overtly mentioned. Thus, sentences such as the following are the norm, whether uttered at the beginning or in the middle of a conversation:

(1) Kattibela pid-o-s-o=kha=lo ni? at.what.time give-3[s]o-PRF-[SBJV.PST.3sA.]3[s]o-NMLZ $2=$ SURP EMPH 'At what time has (he) given (it) (to her)?'

(CLLDCh4R04S02.1173)

In response to this challenge, we use a strictly semantic definition of argumenthood: referential phrases instantiate arguments iff their existence and role is logically entailed by the semantics of the lexical predicate and cannot be derived from any other element in the linguistic or nonlinguistic context.

Arguments are classified according to their number and the role they occupy, following the definitions in Bickel et al. (2010):

- The sole argument of a monovalent predicate is called S.

- The two arguments of a bivalent predicate are called A and P. A is the argument having more proto-agent properties than the other one (in the sense of Dowty: 1991a), which is called $P$ here.

- The three arguments of a trivalent predicate are called A, T ("theme") and G ("goal"). A is determined as above. Of the remaining two, $\mathrm{T}$ is (physically or metaphorically) moving relative to the stationary G.

A central concept that will be used in the discussion of valency patterns below is the frame. A frame is defined as a specific type of argument realization, as estab- 
lished by case marking and agreement. In describing frames, the following formalism (similar to the one used in the database used in the Leipzig Valency Classes Project (Hartmann et al. 2012)) will be used:

- $\quad$ predicate with set of core roles X, Y: $\{X \text { Y V }\}^{3}$ (e.g., $\{\mathrm{S} \mathrm{V}\}$ : intransitive frame)

- $\quad$ role $\mathrm{X}$ marked by case C: X-C (e.g., T-NOM: T marked by nominative)

- $\quad$ roles X, Y associated with agreement marker sets a and b: V-a(X).b(Y) (e.g., $\{\mathrm{V}-\mathrm{a}(\mathrm{S}) . \mathrm{o}(3 \mathrm{~s})\}$ : S linked to agreement marker set 'a', dummy third person singular in agreement marker set 'o')

Frames are basically lexically determined and then modified by syntactic factors. The basic frames set by the lexicon are discussed in $\S 3$ Valency patterns. The syntactic factors modifying these can be split into "classical” differential marking patterns affecting the marking of only one element in a frame and into valency alternations affecting several or all elements in a frame. The former are outside the scope of the present study and are thus only briefly touched upon in the section on case marking. The latter are of vital interest and are discussed in detail in §4 Valency alternations.

In this chapter we focus on "simple" frames, i.e. frames involving at most one predicate. Complex frames that combine more than one verb (e.g., through verb compounding, serial-verb-like structures or control constructions) are outside our current purview.

\subsection{Case}

\subsubsection{Markers}

Most case markers in Chintang are morphologically bound elements (suffixes), but a few are morphologically independent particles. The sets of case markers for arguments and adjuncts are not disjoint: all markers that can be used to mark core roles can also be used to mark peripheral roles. In particular:

- The zero-marked form (called nominative here) is used for $\mathrm{S}, \mathrm{P}$, and certain $\mathrm{T}$ and $\mathrm{G}$, but also for specifying times and adjunct destinations. The nominative will not be glossed in the examples; any bare nominal is in the nominative. ${ }^{4}$

- The ergative $(-\eta a)$ is used for the A of most bivalent and trivalent verbs, but also for instruments (the majority of which are considered a T here), causes, and, in combination with locative suffixes, for sources and objects of comparison.

3 The curly brackets are not used in the database but are useful to set off role sets from the surrounding text.

4 There is one single exception: the interrogative pronoun sa- 'who' takes a non-zero nominative ending in -lo. 
- The locatives (-be? and -i?) are used for certain G, but also for adjunct places and destinations.

Table 1 is an exhaustive list of case markers in Chintang. Altogether there are 20. Markers borrowed from Nepali have been included where they occupy a functional niche that did not have a dedicated marker before. Note that not all markers are compatible with all nominals. For instance, several suffixes such as -?ni [DIR] or -khi? [MOD] can only occur with deictics. Other markers do not have such restrictions but also occur with non-nominals. For instance, gari [TMP.LOC] also combines with adverbs and verbs.

Tab. 1: Case markers.

\begin{tabular}{|c|c|c|c|c|c|}
\hline$-\emptyset$ & NOM & nominative & $-k o$ & GEN & genitive \\
\hline$-(b a) m u$ & LOC.DOWN & inferior locative & -lam & PERL & perlative \\
\hline$-(b a) n d u$ & LOC.UP & superior locative & -lantĩ & FIN & finalis \\
\hline$-(b a) y u$ & LOC.ACROSS & ulterior locative & likhi & EQU & equative \\
\hline$-b e ?$ & $\mathrm{LOC}_{1}$ & locative I & $-? n i$ & DIR & directional \\
\hline gari & TMP.LOC & temporal locative & $-n \dot{t \eta}$ & $\mathrm{COM}$ & comitative \\
\hline$-i p$ & $\mathrm{LOC}_{2}$ & locative II & $-\eta a$ & ERG & ergative \\
\hline kherna & TMP.ABL & temporal ablative & pache & POST & postessive \\
\hline -khi? & MOD & modalis & -patti & AREA.LOC & area locative \\
\hline -khiPnin & MANNER & manner case & somma & TERM & terminative \\
\hline
\end{tabular}

\subsubsection{Differential case marking}

The most important differential case marking pattern of Chintang concerns the A argument. The ergative on A is only obligatory with nouns, deictics, and numerals. It is generally optional with first and second person pronouns, which in turn differ from each other in their inclination to mark it: it is relatively frequent with ani [1pi] and hani [2p] (about half of all instances), very rare with akka [1s], anci [1di], hana [2s], and hanci [2d] (a little less than $10 \%$ of all instances at most, only attested in elicitation at least), and ungrammatical with ancaya [1de] and anaya [1pe] (possibly due to haplology: the shape of the ergative marker is - $\eta a$ ). The following examples illustrate fluid A marking with second person pronouns and fixed A marking with third person expressions (3).

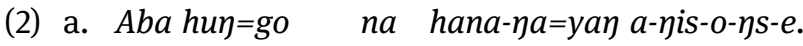
now MED-NMLZ 1 TOP 2s-ERG=ADD 2[s]A-recognize-3[s]o-PRF-IND.PST 'Now you, too, have recognized this.' (suntala_talk.61) 
b. Hana them a-hekt-o-ko huy=go-i??

2s what 2[s]A-cut-3[s]O-IND.NPST MED-NMLZ - LOC $_{2}$

'What are you cutting there?'

(CLLDCh2R14S03.0366)

(3) a. Huĩ-sa-ya jamma kob-o-ko=kha?

MED-OBL-ERG everything pick.up-3[s]o-IND.NPST[.3SA]-NMLZ $z_{2}$

'So it (the camera) picks up everything?'

(CLLDCh2R06S07.441)

b. ${ }^{\star} H u \eta=g o$ angreji pad-e numd-o-ko.

MED-NMLZ ${ }_{1}$ English study-v.NTVZ do-3[s]o-IND.NPST[.3sA]

'He's studying English.'

(elicitation 2010)

The factors governing the presence of ERG on first and second person pronouns are not yet sufficiently understood. It looks like at least three factors enable (though not necessarily favor) the marking of ERG: the presence of deontic modality (the one who should or should not do something being marked by ERG), the conservativeness of the language (ERG is found more often with older speakers and in archaizing registers), and the importance of the referent in A for the truth value of a clause (if replacing the referent could easily make the statement false it can be marked by ERG).

Another differential marking pattern is fluid destination marking. If a $P$ or $G$ argument has a spatial destination meaning and can be marked by one of the various locative and directional cases, it can also occur in the nominative (zeromarked):

(4) a. Bha-ndu-Pni u-kac-ce-ke elo? PROX-LOC.UP-DIR 3s-come.up-d-IND.NPST or

'Are they coming up here?'

(CLLDCh1R04S01.446)

b. Maita a-kac-ce-ke elo?

parents.home[Nом] 2s-come.up-d-IND.NPST or

'Are you coming up to your parent's home?'

(CLLDCh3R05S01.1096)

This alternation is not possible where the locative marks other functions than those mentioned above (e.g., with static locations). The semantic difference between the variants is not clear yet. 


\subsection{Agreement}

\subsubsection{Markers}

Verbs regularly index person, number, and clusivity of one or two arguments, depending on lexical as well as on syntactic factors to be discussed below (§4). The possible values for these features are as follows:

- 3 persons: speaker [1], hearer [2], other [3]

- 3 numbers: singular [s], dual [d], plural [p]; in some forms also non-singular [ns] generalizing over dual and plural

- 2 clusivity values (only with [1ns]): inclusive [i], exclusive [e]

Table 2 contains a list of all argument markers and their global functions (i.e. what all paradigm cells containing them have in common). ${ }^{5}$ They are ordered according to their slots in the verbal complex.

Tab. 2: Agreement markers.

\begin{tabular}{llll}
\hline$a-$ & $2 \mathrm{~S} / \mathrm{A}$ & $-n i$ & $2 / 3 \mathrm{p}$ \\
$k h a-$ & $1 \mathrm{nsO}$ (Sambugaũ) & $-i$ & $1 / 2 \mathrm{pS} / 0$ \\
$m a-$ & $1 \mathrm{nseO}$ (Mulgaũ) & $-c e$ & $\mathrm{~d}$ \\
$m a i-$ & $1 \mathrm{nsiO}$ (Mulgaũ) & $-u$ & 30 \\
$n a-$ & $3>2$ & $-\eta$ & $1 \mathrm{sA}$ \\
$u-$ & $3 \mathrm{~S} / \mathrm{A}$ & $-m$ & $1 / 2 \mathrm{pA}$ \\
$-\eta a$ & NPST.1sS/0 & $-c e$ & $3 \mathrm{nsO}$ \\
$-n a$ & $1 \mathrm{~s}>2$ & $-\eta a$ & $\mathrm{e}$ \\
$-\eta$ & $1 \mathrm{sS} / 0$ & & \\
\hline
\end{tabular}

This list shows that markers in Chintang do not define a single alignment pattern. Some are accusative (e.g., $a$-), some are ergative (e.g., -i), others are neutral (e.g., -ni). Under such circumstances talking about, for instance, "S agreement" obtains a special meaning: this term does not indicate a set of dedicated markers each of which is both necessary and sufficient for $\mathrm{S}$ but rather the set of affix combinations which as a whole indicate that there is an $\mathrm{S}$ and indexes some features of it.

5 The analysis here differs in some regards from Bickel et al. (2007a) and other earlier work, but we defer discussion of this to another occasion. Suffice it to say that the Chintang paradigms support a substantial number of competing analyses.

Note that elsewhere in this chapter glosses are not based on the global (abstract, ambiguous) function of markers, but on their local (concrete, disambiguated) functions in order to improve readability. The local function of a marker is defined as the function it marks in a concrete form. For instance, $a$ - has the global function [2S/A] and $-m$ has [1/2pA]. However, the form $a-k h e m s-u-$ ku-m 'you (PL) hear it' will be glossed [2A-hear-3[s]P-IND.NPST-2pA], where the markers are disambiguated by the morphological context. 
The situation is further complicated by the fact that $\mathrm{S}$ agreement typically, but by no means always indexes $S$ in the semantic sense that we proposed above (i.e. in the sense of: 'the argument of a predicate that lexically entails only one argument'). For example, in a specific kind of experiential construction discussed below, S agreement (or "S-AGR" for short) is in a frozen third person "dummy" form, the real $S$ experiencer argument being realized as a possessive phrase in the clause. Similar caveats hold for A agreement (“A-AGR"): the A-AGR forms typically but not always index an A argument. For O agreement ("O-AGR"), the situation is even more complex. While the forms typically index $\mathrm{P}$ or $\mathrm{G}$ arguments, they can also index $\mathrm{T}$. These choices all depend on the chosen valency frame.

\subsubsection{Differential agreement}

There are two differential marking patterns that affect agreement only. However, unlike differential case marking, which is general across frames, both of these are intimately linked to specific frames. One of the differential agreement patterns is the variable linking of A-AGR in one of the transitive experiential frames, and we will discuss this below. The other differential agreement pattern is tied to predicates undergoing long-distance agreement with dependent infinitives. This pattern is outside the scope of the present study.

\subsection{Word order}

Word order in Chintang is "free", that is, it is directly conditioned by information structure and similar factors and is not mediated, for instance, by role or clause type. So far, no detailed analysis has been carried out concerning which factors are involved and how precisely they influence word order. What seems safe to say is that the most important contrast is between old and new information. Old referents tend to be mentioned earlier than new referents. Referents which are so easy to access that the first impulse would have been not to mention them at all may be inserted in an afterthought position behind the verb. Otherwise the last position in the clause is by default occupied by the predicate and associated particles. These tendencies yield the most frequent word orders SV, APV, and AGTV.

The analysis of the connection between word order and information structure in Chintang is further complicated by the existence of several information structuring particles and clitics such as na [TOP] and =ta [FOC]. What is most important for the present study is that word order is never directly conditioned by valency. Observable correlations such as the fact that the referent occupying A tends to precede $\mathrm{P}$ or $\mathrm{G}$ and $\mathrm{T}$ where several arguments are expressed overtly reflect correlations between roles and information structure (in this case the well-known tendency for agents to stay topics over longer stretches of discourse; cf. Du Bois 2003). 


\subsection{Phrase structure}

The most important syntactic unit in Chintang is the clause, consisting of a predicate and associated referential phrases (NPs). Phrases below or above this level are of marginal importance. NPs in Chintang are by default head-final, but dependent elements can follow the head under similar conditions as referents moved into the postverbal afterthought position. Possessive relations can be marked by -ko [GEN] on the possessor, by a prefix on the possessum indexing person/number/clusivity of the possessor, or by both markers simultaneously. Numerals take classifiers indexing referential properties of the head noun (human vs. non-human). All other markable properties associated with the NP as a whole, such as number and case, are only marked on the head noun.

So far we have found no evidence for verb phrases or modifier phrases, but we note that research in this area is still very rudimentary.

\section{Valency patterns}

This section lists all 15 predicate frames that we have identified so far in our lexicographic work on a total of 663 verbs (Rāì et al. 2011). 11 frames are employed by several verbs. The remaining 4 are only employed by a single verb each. In the following, for each frame we indicate in brackets the number of verbs that we have (so far) found to appear with it and the percentage that this number makes up of all verbs in the lexicon. This does not necessarily mean that each verb counted always or even most frequently occurs in the given frame or that it occurs always in the same frame. In fact, as we will show below, it is characteristic of the Chintang lexicon that verbs are compatible with several frames at once. ${ }^{6}$

As valency patterns and valency alternations are to be discussed separately (following the editors' guidelines), it is necessary to define which frames are to be viewed as basic and which as derived. The criterion we use to make the distinction is the number of conditions for frame components. A component is considered to be the more basic if it is found under more conditions. For instance, among others, there are the monotransitive frames $\{\mathrm{A}-\mathrm{ERG} \mathrm{P}-\mathrm{NOM} \mathrm{V}-\mathrm{a}(\mathrm{A}) . \mathrm{o}(\mathrm{P})\}$ and $\{\mathrm{A}-\mathrm{NOM}$ $\mathrm{P}-\mathrm{NOM} \mathrm{V}-\mathrm{a}(\mathrm{A}) . \mathrm{o}(\mathrm{P})\}$. Of these, the frame with the ergative is licensed by many more conditions that the nominative, viz. by all but a few first and second person pronouns. Therefore, we consider it as basic.

However, there are two prominent cases where basicness cannot be as easily determined. These are the S/O and S/A alternations. S/O ambitransitivity is determined by semantic factors associated with the predicate or the clause as a whole

6 Also note that for this reason the percentages given for each frame do not sum up to 100 . 
(see $\S$ 4.1.1), S/A detransitivization is determined by what can be approximated as the quantifiability of $\mathrm{P}, \mathrm{G}$, or $\mathrm{T}$ (see $\S 4.1 .2$ ). Both have in common that there are not more conditions triggering them than conditions excluding them. The reason why we treat them as alternations here is that it is easier to describe them as deviations from a default pattern than the other way round.

Intransitive frame $\{\mathrm{S}-\mathrm{NOM} \mathrm{V}-\mathrm{s}(\mathrm{S})\}$ (304 verbs, $45 \%$ ). This is the frame which is allowed by most verbs. The number of verbs which allow only the intransitive frame is much lower - it amounts to only 131 verbs (20\%). Examples of verbs taking the intransitive frame are bhopt- 'be round', pind- 'run', ta- 'come', yans'shake', hap- 'cry', e.g.

(5) Ama, nunu hap-no.

mother baby cry-IND.NPST[.3ss]

'Mum, the baby is crying.'

(CLDLCh3R01S02.293)

Monotransitive frame AA-ERG P-NOM V-a(A).o(P)\} (298 verbs, 45\%). This frame comes equal to the intransitive frame when considering the number of verbs allowing it. However, when it comes to which frame is more "central" for verbs (in the sense that other frames can be derived from it), the monotransitive frame occupies a much stronger position. This is because most of the verbs which allow the intransitive frame also allow the monotransitive frame (via regular S/O ambitransitivity, cf. § 4.1.1), leaving only a relatively small percentage of strictly intransitive verbs. Since arguments are covert most of the time, the key indicator for the monotransitive frame is the bipersonal agreement found on the verb. ${ }^{7}$ Examples for verbs taking this frame are kam- 'fasten', set- 'kill', tup- 'meet', khems- 'hear', ca- 'eat':

(6) Rame-na=ta biskut c-o-hatt-e.

Rame-ERG=FOC cookie eat-3[s]o-AWAY.TR-IND.PST[.3sA]

'Rame ate up the cookie.'

(CLLDCh1R07S02.876)

The monotransitive frame has a detransitivized variant that is distinct from the intransitive frame and involves nominative case on and S-agreement with A. See $\S$ 4.1.2 for data and discussion.

Direct object ditransitive frame $\{$ A-ERG G-LOC T-NOM V-a(A).o(T)\} (118 verbs, $18 \%)$. This is the most frequent trivalent frame in Chintang. As observed in Bickel et al. (2010), the frame does not impose specific semantic constraints beyond a

7 However, this is complicated by the fact that there are a few but very frequent homophonous forms in the indicative past and in the imperative which do not make it clear whether there is $\mathrm{S}$ AGR or A+O-AGR. 
fairly general sense of caused motion, unlike the other frames which are specifically associated with enclosures or physical manipulations of the $\mathrm{G}$ argument or with recipient and beneficiary interpretations of G. Examples for verbs with the direct object frame are choys- 'deliver', os- 'throw', ritt- 'spill', pays- 'send (a person)', yuns- 'put', e.g.

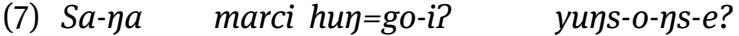 \\ who-ERG chilli MED-NMLZ ${ }_{1}^{-L_{0}}$ put-3[s]o-PRF-IND.PST[.3sA] \\ 'Who put the chilli there?' \\ (CLLDCh1R05S01.115)}

Primary object ditransitive frame AA-ERG G-NOM T-ERG V-a(A).o(G)\} (79 verbs, $12 \%)$. The bulk of verbs in this frame involve physical manipulation using an instrument where manipulation may be anything from an addition of material, resulting in enclosures (as in the example), to a change of shape or even destruction. There is a tendency for etymologically related verbs designating similar processes, where one verb focusses on movement and uses the double object pattern (e.g., ams- 'shoot, hurl') and the other focusses on the physical impact on $G$ and uses the primary object pattern (apt- 'shoot, hit (by shooting)'). Examples for verbs with the primary object frame are dhikt- 'cut', ok- 'peel', thup- 'hit', ik- 'scoop', dipt'wrap', e.g.

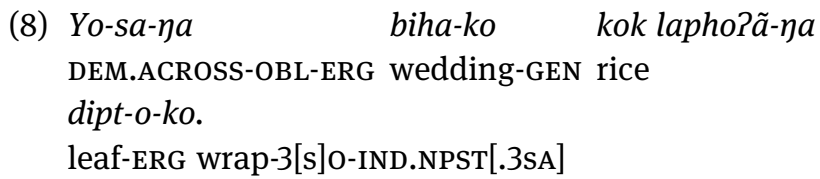

'That guy is wrapping the rice for the wedding into leaves.'

(elicitation 2010)

Double object ditransitive frame $\{$ A-ERG G-NOM T-NOM V-a(A).o(G)\} (37 verbs, $6 \%$ ). This pattern is not very frequent but interesting because it marks $G$ and $T$ alike and because many of the verbs licensing it are often assumed to be prototypical for ditransitives (Malchukov et al. 2010). For almost all verbs taking this frame, the argument mapped to $\mathrm{G}$ is an animate being that is indirectly affected by an action (typically, but not necessarily, as a beneficiary), although there are also some verbs that have a meaning of 'covering, enclosing', overlapping with the primary object verb semantics (Bickel et al. 2010). While $\mathrm{G}$ and $\mathrm{T}$ are treated alike in terms of case, agreement selects the $\mathrm{G}$ argument as aligned with P. Examples are cand- 'feed', cind- 'teach', thikt- 'spread out for', khutt- 'bring', pid- 'give':

(9) Hani-bakhra-ce sa-na ghãsa pid-u-c-e?

2pPoss-goat-ns who-ERG grass give-3o-3nso-IND.PST[.3sA]

'Who gave grass to your goats?'

(CLLDCh1R07S03.068) 
A few verbs license both the primary and the double object frame. This phenomenon is not viewed as differential case marking here because it is limited to five verbs. For instance:

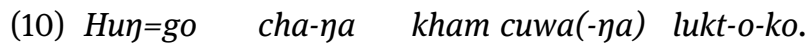
MED-NMLZ 1 child-ERG floor water(-ERG) pour-3[s]o-IND.NPST[.3sA] 'That child pours water onto the floor/pours the floor with water.' (elicitation 2010)

Intransitive experiential frame $\{\mathrm{S}-\mathrm{GEN} / \mathrm{NOM}$ poss(S)-N.EXP-NOM V-s(N.EXP) $\}$ (11 verbs, $2 \%$ ). This pattern is typical for Kiranti languages and involves what Bickel (1997) calls a possessive of experience construction, in which the medium of a psychological or physiological experience is coded as its possessor. As a result, the $\mathrm{S}$ (the experiencer) argument can be marked by either GEN or NOM, ${ }^{8}$ the experiential noun ("N.EXP") has a possessive prefix, and the verb agrees with the noun. Although there are not many verbs using this pattern the combination of verbs with various experiential nouns covers a wide semantic range and sets the base for its being the default for expressing experiences in Chintang. In many cases verb-noun combinations have become lexicalized. We deal with this by treating as a single verb any combination where the verb, the noun, or both elements no longer exist as independent lexemes (e.g., dik-ris- 'hesitate' instead of dik ris- [X turn.around]). Examples for verbs taking this frame are ninwa-chit- 'be sad', somsi- 'be satisfied', mik-id- 'feel sleepy' (with lexically dependent components), or (with independent components) ta- 'come', lond- 'come out', kat- 'come up':

(11)

Abui, ak-ko a-kipma=lo kad-e!
wah 1s-GEN 1sPOss-fear=SURP come.up-IND.PST[.3ss]
'Wah, I'm afraid!'
(CLLDCh3R11S04.307)

Transitive experiential frame I \{A-ERG P-NOM poss(A)-N.EXP-NOM V-a(A/3s).o(P)\} (6 verbs, $1 \%$ ). The transitive experiential frame is an alternative to the corresponding intransitive frame that is used when one wants to include the stimulus ('be afraid of', 'feel sad about' etc.). This, however, is rarely ever done - there are only a handful of attestations of the transitive experiential frame in our corpus and very few verbs that license it, e.g., nin-nus- 'be happy about', som-tukt- 'feel sorry for, love' (both with univerbation of N.EXP and V), katt- 'bring up' (with lexically independent experiential nouns). Notwithstanding, this frame has preserved a highly

8 We have not treated this as differential S marking because the same alternation is available for possessors outside this construction, so its conditions are part of regular NP syntax rather than case syntax in the clause. 
unusual differential agreement pattern. A (the experiencer) and $\mathrm{P}$ (the stimulus) are marked in the same way as in the monotransitive frame. Like in the intransitive experiential frame, an experiential noun is required which indexes the experiencer via a possessor prefix. This is shown in example (12).

(12) Hana-na hun-ce i-rek $a-k a t t-u-c-e$ ?

2s-ERG MED-ns 2sPOss-anger 2[s]A-bring.up-30-3nso-IND.PST

'Are you angry with them?'

(elicitation 2011)

In this example the scenario marked by the inflection is $2 \mathrm{~s}>3 \mathrm{~ns}$, just as is expected from the mapping of the experiencer to A and the stimulus to P. Alternatively, AAGR can be filled by dummy 3s, ${ }^{9}$ O-AGR staying with P:

(13) Hana-ya hun-ce i-rek

katt-u-c-e?

2s-ERG MED-ns 2sPoss-anger bring.up-3o-3nso-IND.PST[.3sA]

'Are you angry with them?'

(elicitation 2010)

This alternation is constrained by hierarchical factors. Dummy third person agreement is ungrammatical with high (first and second person) $\mathrm{P}$ and, for some speakers, with low (third person) A.

Transitive experiential frame II \{A-ERG P-NOM poss(A/P)-N.EXP-NOM V$\mathrm{a}(\mathrm{A}) . \mathrm{o}(\mathrm{P})\}$ (2 verbs, < 1\%). This rare frame is only licensed by two etymologically related verbs, set- 'kill' and sett- 'kill for somebody'. The frame includes the experiential noun som 'liver' and has the meaning 'be satisfied with' or 'satisfy', depending on whether the experiencer is mapped to A (14a) or to P (14b).

a. Akka hun-ce a-som sett-u-cu-h-ẽ.

1s MED-ns 1sPoss-liver kill.for-30-3nso-1sA-IND.PST

'I was satisfied with them.'

(elicitation 2010)

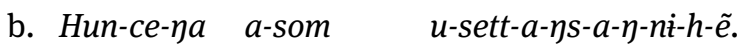

MED-ns-ERG 1sPoss-liver 3A-kill.for-PST-PRF-PST-1so-3p-1so-IND.PST

'They have satisfied me.'

(elicitation 2010)

9 Another theoretical possibility is that A-AGR is triggered by the experiential noun (rek). There is no way to distinguish between this possibility and dummy agreement. We went for the latter solution here because the notion of dummy agreement is independently needed for Chintang, viz. in the analysis of "transimpersonal" verbs as discussed below. By contrast, we know of no case in Chintang where nouns that enter lexicalized combinations with a verb trigger A-agreement. 
With the meaning 'be satisfied with', the experiencer is mapped to A (here incidentally in the nominative rather than ergative because it is first person; cf. §2.2) and the stimulus to $P$. This variant resembles the transitive experiential frame, but without the possibility of filling A-AGR with dummy 3s. With the meaning 'satisfy', the experiencer is $\mathrm{P}$ and the stimulus (now taking on an active role in achieving satisfaction) is A. This variant is similar to the monotransitive frame but still features the experiential noun som, which is now possessed by P. The possessor of this noun may thus be said to invariably index the experiencer regardless of the role it is mapped to.

Transimpersonal frame I $\{\mathrm{S}-\mathrm{NOM} \mathrm{V-a(3s).o(S) \}}$ (4 verbs, < 1\%). This is a deponent frame, that is, there is a mismatch between its morphosyntax and its semantics: the verb has bipersonal agreement though there is only a single argument. ${ }^{10}$ The role of this argument is linked to O-AGR, and A-AGR is filled by a dummy 3s. In example below, the matrix $A$ is $1 p$. If this $A$ was indexed on the deponent embedded verb lokt- 'boil' as well ('we brought it to a boil'), the expected form would be lokt-u-m [boil-3[s]o-[SBJV.PST.]1pA]. What we find, though, is lokt-o [boil[SBJV.PST.3sA.]3[s]o], with A-AGR not being linked to $1 \mathrm{p}$ but filled by a dummy:

(15) Sop-mayan=go sambok sojho=ta

husk-PASS.PTCP-NMLZ 1 millet directly=FOC

$\begin{array}{ll}\text { lokt-o }=\text { go } & \text { cuwa-i? } \\ \text { boil-[SBJV.PST.3SA.]3[s]o-NMLZ } & \text { water-LOC } 2 \\ \text { put.into-3[s]o-[SBJV.NPST.]1pA }\end{array}$

tis-u-m kina thukt-u-m nusayan yans-o-ko.

SEQ cook-3[s]o-[SBJV.NPST.]1pA CONCS be.okay.for-3[s]o-IND.NPST[.3sA]

'It is also okay if we put the husked millet directly into the boiling water and cook it.'

(thi_numma.20-21)

The other three verbs taking this frame are simd- 'fall asleep (of a limb)', tapt- 'be wobbly, stagger', and chapt- 'be destined to'. The transimpersonal frame cannot be productively extended to other verbs to indicate spontaneity or other conceivable functions.

Transimpersonal frame II $\{\mathrm{S}-\mathrm{NOM}$ V-a(S).o(3s) $\}$ (2 verbs, < 1\%). The second transimpersonal frame is rather similar to the first one but links $\mathrm{S}$ to A-AGR and has a dummy 3s in O-AGR. It is used by two semantically similar verbs, pukt- 'grow' and phatt- 'bloom, flower, ripen'. This frame is highly exceptional within the morphosyntactic system of Chintang in that it allows a link between A-AGR and a NOMmarked argument.

10 For a recent survey of “transimpersonals” in other languages, see Malchukov (2008). 
(16) Jamma u-phatt-o-s-e.

all 3pA-bloom-3[s]o-PRF-IND.PST

'All things are in bloom.'

(CLLDCh3R09S05.237)

Copular frame $\{$ Theme-NOM Rheme-NOM V-s(Theme) (3 verbs, $<1 \%$ ). This frame is regularly used with nominal and adjectival predicates (called "Rheme" here). Besides the use with verbs (yun- 'be (there)', lis- 'be, become', nins- 'look like') as in (17a) and uninflected verboids (manchi 'be not (there)', maha? 'be not') as in (17b) it is also frequently found without any verb. In that case the Rheme is mostly, but not necessarily, marked by the nominalizer $=k h a$, see (17c) and (17d).

a. Cha-ce na allare u-li-no.

child-ns TOP childish 3[p]s-be-IND.NPST

'The children are childish.'

(CLLDCh1R06S02.1057)

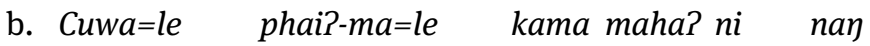

water=RESTR fetch-INF=RESTR work be.not EMPH but

a-phuwa-ko.

1sPoss-elder.brother-GEN

'But fetching water all the time is not my brother's job.'

(exp_uni.316)

c. Hun na cãdi=kha.

MED TOP silver=NMLZ

'That is silver.'

(CLLDCh2R11S06.064)

d. Okho, ba them?

oho PROX what

'Oho, what's this?'

(CLLDCh4R03S03.0543)

Minor frames. The remaining frames are only attested with single verbs:

\{A-NOM P-NOM V-s(A)\} with si- 'feel':11

(18) Cha sinsawa si-a-s-e.

child hunger feel-PST-PRF-IND.PST[.3ss]

'The child is hungry.'

(elicitation 2011)

11 This frame is also used by cind-ci- 'learn', which is a lexicalized reflexive of cind- 'teach', so the frame is predictable from the default frame for cind- $\{\mathrm{A}-\mathrm{ERG}$ G-NOM T-NOM V-a(A).o(G)\} and the behavior of the reflexive alternation (cf. § 4.2.1). 
\{A-NOM P-NOM V-a(P).o(A)\} with phatt- 'reach (an age), take (time for doing sth)'

(19) Sãcci=lo jaũle-ce assu phatt-u-ku-ce? really=SURP twin-ns how.much reach-30-IND.NPST-[3sA.]3nso 'How old are the twins really?' (CLLDCh1R02S04b.1451)

\{A-ERG T-NOM G-NOM V-a(A).o(T)\} with nakt- 'ask for':

(20) Huĩ-sa-na akka a-hedphon-ce nakt-u-c-e. MED-OBL-ERG 1s 1sPoss-headphone-ns ask.for-3o-3nso-IND.PST[.3sA] 'He asked me for my headphones.' (elicitation 2011)

\{A-NOM P-LOC V-s(A)\} with ya-khamd- 'chew, gnaw':

(21) U-te?-ce-be ya=ta=kham-no. 3sPoss-clothes-ns-LOC ${ }_{1}$ PVB=FOC=chew-IND.NPST[.3ss] 'She's chewing on her clothes.' (CLLDCh2R05S01.225)

\section{Valency alternations}

In the following we discuss regular, productive alternations between frames, i.e. patterns where verbs with one and the same core lexical meaning are compatible with two or more frames. We limit our attention to alternations that affect at least two elements simultaneously, typically case and agreement alike. This excludes patterns like differential case marking and differential agreement, which affect only a single element at a time (cf. $§$ 2.2.2 and $\S$ 2.3.2 above).

\subsection{Alternations without a dedicated marker}

\subsubsection{S/O ambitransitivity}

$\mathrm{S} / \mathrm{O}$ ambitransitivity of a verb is given when it can take both the intransitive frame \{S-NOM Vs(S)\} and the monotransitive frame $\{\mathrm{A}-\mathrm{ERG} \mathrm{P}-\mathrm{NOM} \mathrm{V-a(A).o(P) \} .} \mathrm{Two}$ closely related alternations link the intransitive frame to a direct object ditransitive $\mathrm{T}$ (S/T ambitransitivity) or to a primary object ditransitive $\mathrm{G}$ (S/G ambitransitivity). As indicated by the names, the $S$ of the intransitive frame corresponds to the argument triggering O-AGR in one of the transitive frames, which may be $\mathrm{P}, \mathrm{T}$, or G (cf. 
$\S 2.3)$. Collectively we refer to this set of alternations as "S/O alternations". A typical example is the following:

(22) a. Saĩli, kana-phak na ba-tta=kha

third.daughter 1pePOss-pig TOP PROX-EXT-NMLZ 2

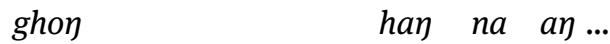

grow.big[.sBJV.NPST.3ss] COND TOP QTAG

'Saîli, suppose our pig grew as big as this ...'

(CLLDCh1R06S03.0151)

b. $B a=g o$ phak them-ma ba-tta ghons-o-ns-e?

PROX-NMLZ 1 pig what-ERG PROX-EXT grow.big-3[s]0-PRF-IND.NPST[.3sA]

'What has let this pig grow this big?'

(elicitation 2010)

This alternation is to some extent reminiscent of inchoative/causative alternations, and the verb class defined by it loosely corresponds to what is known as unaccusative verbs. The class is particularly large in Chintang. In the present version of the Chintang dictionary there are 304 verbs taking the intransitive frame. 140 or about $46 \%$ of these also take a transitive frame. Of all 298 verbs taking the monotransitive frame, 76 or $26 \%$ are $\mathrm{S} / \mathrm{O}$ ambitransitive. The numbers for the ditransitive classes are 37/118 (31\%, direct object ditransitive) and 24/79 (30\%, primary object ditransitives). There are no S/O ambitransitive double object ditransitives. The proportion of S/O ambitransitive verbs in all verbs is 140/663 (21\%). Figure 1 summarizes these figures.

Unlike better-known inchoatives and unaccusatives, however, the Chintang alternation is also fully productive with verbs that have a clearly identifiable agent.

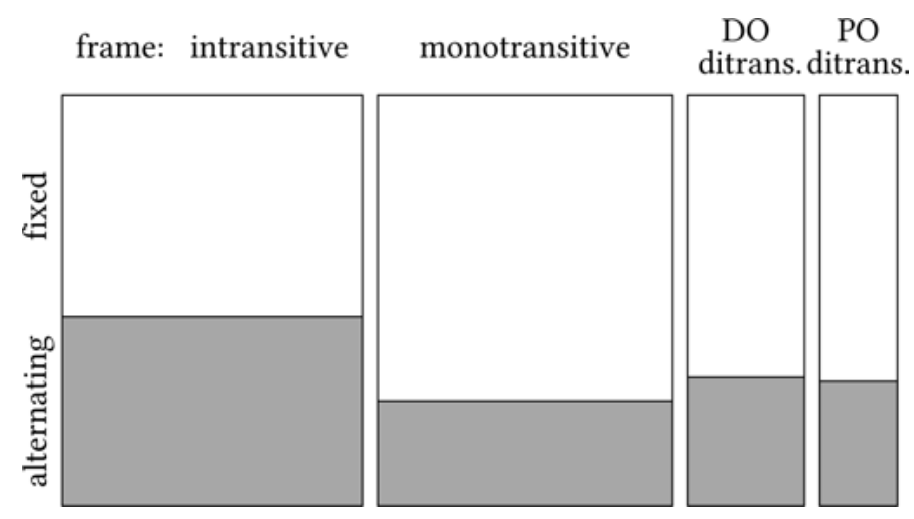

Fig. 1: X-axis: most frequent frames in the lexicon; y-axis: proportion of verbs that are attested only with this frame ('fixed') vs. with S/O alternations ('alternating'). Tile sizes are proportional to frequencies. 
The intransitive variant is used when agents are suppressed for discourse reasons and this results in passive translations, like in the following example:
(23)

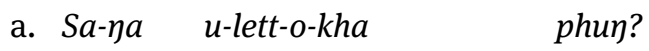 who-ERG 3[p]A-plant-3[s]o-NMLZ 2 flower 'Who planted the flower?' (CLLDCh3R07S01.953) .
b. Makkai-ce u-lett-a-ns-e. maize-ns 3[p]s-plant-PST-PRF-IND.PST 'The maize plants have been planted.' (field notes 2010)

The availability of the S/O alternation is largely predictable and this makes the "class" of S/O ambitransitive verbs atypical of a lexical class in the sense that it would be based on idiosyncratic properties. Instead, basically any verb that may be telic and involves a change of state can participate in the alternation. ${ }^{12}$ This also means that there is no lexical contrast between, for instance, the monotransitive class and S/P ambitransitives - there is only one monotransitive class, and the semantics of each of its members determine whether it is open to the S/P alternation or not. The intransitive variant is used to place a focus on the result rather than on the dynamic accomplishment of an action.

An interesting property of $\mathrm{S} / \mathrm{O}$ ambitransitivity is that there is no obvious basic variant. The criterion of counting conditions (cf. $\S 3$ ) is not of use here. If one defines basicness via token frequency one also gets ambiguous results: some verbs are more often used with the intransitive frame, others more often with a transitive frame. For instance, both verbs in the example above are only attested in the variants in (22a) and (23a) in the Chintang corpus (intransitive for ghoys-, transitive for lett-) and were only revealed to be ambitransitive by field work.

\subsubsection{S/A detransitivization}

$\mathrm{S} / \mathrm{A}$ detransitivization is an alternation between a regular transitive frame and a detransitivized variant that licenses an identical role set (i.e. no argument is suppressed) but with different coding properties: the A argument must always be marked with NOM and triggers S-AGR on the verb; the other arguments retain their

12 There are a few exceptions which can, however, be explained by assuming competition between the alternative frame and a different lexeme. For instance, chukt- 'jump down, land' cannot be used transitively because there is thand- 'bring down, land'. 
case marking, but do not trigger O-Agreement. Four examples illustrate this (variants a and c fully transitive, variants $b$ and d detransitivized):13

(24) a. Debi-na seu kond-o-ko.

Debi-ERG apple look.for-3[s]o-IND.NPST[.3sA]

'Debi is looking for an apple.'

(elicitation 2010)

b. Debi seu kon-no.

Debi apple look.for-IND.NPST[.3ss]

'Debi is looking for apples.'

(elicitation 2010)

c. Abo sa tac-c-o.

now meat bring-d-[3sA.]3[s]o

'Now let's bring the meat.'

(elicitation 2010)

d. Abo sa tac-ce.

now meat bring-[1]d[is]

'Now let's bring (some) meat.'

(elicitation 2010)

Beside the identical role set there is one more important difference to S/O ambitransitivity: the S/A alternation does not depend on verb semantics but solely on referential properties; it is therefore available for all transitive verbs.

The property that triggers detransitivization may be approximated as specificity: specific object referents trigger the transitive frame (A-ERG and both A-AGR and O-AGR), non-specific ones detransitivization (A-NOM and S-AGR with A) (Schikowski 2013). The relevant role is always the one that is linked to O-AGR. For instance, $\mathrm{G}$ is linked to O-AGR with double object ditransitive verbs, and so, as soon as $\mathrm{G}$ gets non-specific, the detransitivized frame is used:

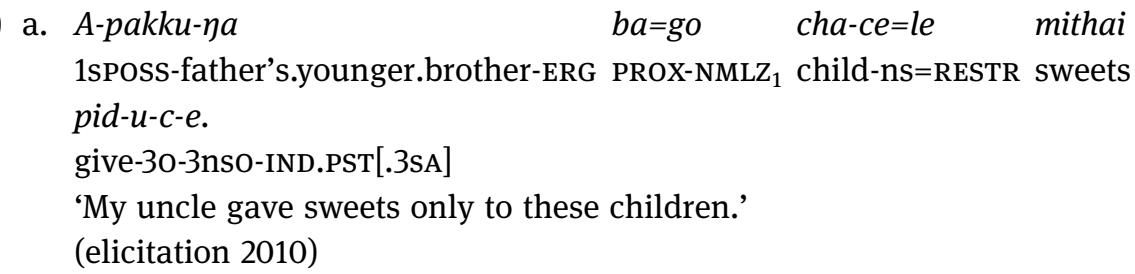

13 The pattern has been variedly analyzed as antipassivization or incorporation in Kiranti languages. For comparison of these analyses, see Bickel et al. (2007b) and Bickel (2011). 
b. A-pakku ba=go mithai=le cha 1sPoss-father's.younger.brother PROX-NMLZ 1 sweets=RESTR child pi-no. give-IND.NPST[.3ss]

'My uncle gives only these sweets to children.' (elicitation 2010)

c. A-pakku cha mithai pi-no. 1sPoss-father's.younger.brother child sweets give-IND.NPST[.3ss] 'My uncle gives sweets to children.' (elicitation 2010)

Like S/O ambitransitivity, S/A detransitivization does not have an easy-to-determine default frame. For some verbs like copt- 'see' the transitive frame is more frequent, for others like $c a$ - 'eat' the detransitivized frame is preferred. A few verbs like rett- 'laugh (about)' are so frequently detransitivized that one would hardly suspect they are not normal intransitive verbs until one hears the transitive variant.

\subsubsection{Reciprocal ambitransitives}

Reciprocal ambitransitives are similar to the other ambitransitives in linking a transitive to an intransitive (or detransitivized) frame. In this alternation both A and $\mathrm{P}$ of the transitive variant correspond to the $S$ of the intransitive variant. The intransitive variant emphasizes the reciprocality of an action. Only four verbs coding actions that frequently are reciprocal take this alternation: hol- 'mix', lapt- 'become/ make friends', lept- 'fuck', tup- 'meet'. Below is an example with tup-.

(27) a. Rame-nin Sita-nin u-tub-a-c-e.

Rame-and Sita-and 3s-meet-PST-d-IND.PST

'Rame and Sita met.'

(elicitation 2010)

b. Rame-na Sita tub-e.

Rame-ERG Sita meet-IND.PST[3s > 3s]

'Rame met Sita.'

(elicitation 2010)

\subsection{Alternations with a dedicated marker}

\subsubsection{Reflexive}

Reflexivity in Chintang is marked by the verbal suffixes -na, -ce, and -ncĩ. The latter two are complementarily distributed: -ce (allomorph $-c \dot{t}$ ) is used in finite singular 
forms, -ncĩ (allomorph - $c \tilde{\imath}$ ) in finite non-singular and in non-finite forms. In some cases -ncĩ is the only marker of plurality, so it is not possible to treat it as a morphologically conditioned allomorph of -ce: compare, for instance, a-khan-na-?a-ce [2[s]s-watch-REFL-IND.NPST-REFL] 'you watch yourself' and a-khay-na-?a-ncĩ [2swatch-REFL-IND.NPST-REFL.ns] 'you watch yourselves'. -na only appears in finite forms (cf. example (30) for the reflexive suffix $-(n)$ ci combined with a non-finite form).

The antecedent of a reflexive is always the A argument (Bickel et al. 2010). The bound role is more variable: with double-object frames, it can be the $\mathrm{T}$ or $\mathrm{G}$ argument:

(28) Joge daktar khan me?-n-a-c-e.

Joge doctor see CAUS-REFL-PST-REFL-IND.PST[.3ss]

'Joge ${ }_{1}$ made himself ${ }_{1}$ see the doctor.' or 'Joge ${ }_{1}$ made the doctor see himself 1 .'

(Bickel et al. 2010: 15)

For direct object (sott- 'move, shift') and primary object frames (tomd- 'support'), the bound role is the one that is linked to O-AGR, i.e. the T argument of direct object and the $\mathrm{G}$ argument of primary object frames:

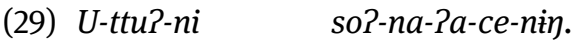

DIST-DEM.UP-DIR move-REFL-IND.NPST[.3SS]-REFL-NEG.NPST

'She doesn't move herself towards up there.'

(CLLDCh1R09S06.0223)

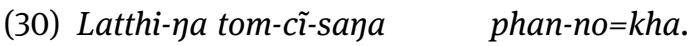

stick-ERG support-REFL-CVB walk-IND.NPST[.3ss]-NMLZ

'He walks supporting himself with (= leaning on) a stick.'

(CLDLCh3R05S02.163)

\subsubsection{Reciprocal}

The expression of reciprocal action requires a special auxiliary construction. The verb base receives the suffix $-k a$ and is fully reduplicated after it. This construct is then supported by the auxiliary lus-. lus- bears all agreement and tense/aspect/ mood information:

(31) Pam-ka-pam lu-ce!

scratch-RECP-scratch AUX-[SBJV.NPST.1]d[is]

'Let's scratch each other!'

(CLLDCh1R06S03.0494) 
The antecedent is $\mathrm{A}$ in monotransitive frames. In ditransitives frames it can be $\mathrm{T}$ or $\mathrm{G}$, which are symmetrically involved:

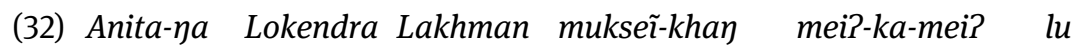
Anita-ERG Lokendra Lakhman recognize-STEM CAUS-REFL-CAUS AUX mett-u-c-e. CAUS-3o-3nso-IND.PST[.3sA]

'Anita introduced Lokendra and Lakhman to each other.' (Bickel et al. 2010: 16)

The bound argument can be $\mathrm{P}$ as in (31) or $\mathrm{T} / \mathrm{G}$ as in (32). Like in the case of reflexives, variability between $\mathrm{T}$ and $\mathrm{G}$ is only observed with double object ditransitives; the other two ditransitive classes bind the argument linked to O-AGR:

(33) Lakkaluppa-be thaĩ-ka-thaĩ u-lu-no.

dancer-LOC 1 drop-RECP-drop 3[p]s-AUX-IND.NPST

'They drop each other near the dancer.'

(exp_wadh_DK.259)

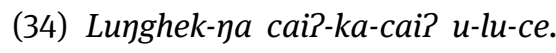

stone-ERG hit-RECP-hit 3s-AUX-[SBJV.NPST.]d

'Let them hit each other with stones.'

(CLLDCh4R04S06.0352)

\subsubsection{Benefactive}

There are three verbal benefactive markers, -bid (< pid- 'give'), -chokt (< chokt'hand, pass'), and -dhett (etymon unknown). Of these -bid is most frequent and most strongly grammaticalized in that it can mark any kind of positive (35a) or negative affection (35b) of an animate entity. -chokt and -dhett retain more concrete meanings, -chokt expressing that an action results in the physical transfer of an object to an animate entity and -dhett emphasising physical (often violent) contact between two animate entities due to an action (37).

(35) a. Bhale rikt-o-kh-o, cock chase-3[s]P-CON-[IMP.2sA.]3[s]o

lab-a- $\eta$-bid- $a-h-\tilde{a}$ ?!

catch-IMP-1so-BEN ${ }_{1}$-IMP-1so-IMP[.2sA]

'Chase down the cock, catch it for me!'

(CLLDCh1R07S07.215) 
b. Jamma na-ca-i-hatt-i-bir-i, ucunulok all 3>2-eat-2p-AWAY.TR-2p-BEN $1-2 \mathrm{p}$ well

yuns-a-n-u-mh-a?. keep-IMP-2p-3[s]o-2nsA-IMP

'It (the cat) might eat everything from you, so keep things well (in the right place).'

(story_cat.227)

(36) Nunu-ce gol os-u-chokt-u-c-a.

baby-ns ball throw-30-BEN 2 -30-3nso-IMP[.2sA]

'Pass the ball to the babies.'

(CLLDCh4R13S05.148)

(37) U-narek-be cahĩ mei-ce kens-a-dhett-a-n-u-m-a.

3sPoss-nose-LOC ${ }_{1}$ SPEC.TOP thing-ns hang-IMP-BEN 3 -IMP-2p-3[s]o-2nsA-IMP

'Hang those things on her ear.'

(CLLDCh4R02S01.1341)

All three benefactives share the same formal behavior: they introduce an additional argument (the affected referent) into the frame of the verb they attach to. This referent is marked by NOM and attracts O-AGR. The rest of the frame (A-AGR and case marking) remains the same. With intransitive verbs, benefactives are very rare but possible. In this case the former $\mathrm{S}$ becomes the $\mathrm{A}$ :

(38) Durga-na lain-be u-eb-a-bid-e-h-ẽ.

Durga-ERG line-LOC ${ }_{1}$ 3sA-stand-PST-BEN-PST-1so-IND.PST

'Durga stood in the line for me.'

(elicitation 2011)

\subsubsection{Augments}

Like other Kiranti languages, Chintang inherited two stem augments $-s$ and $-t$ that can be reconstructed for Proto-Tibeto-Burman as valency-affecting formatives (Wolfenden 1929; Michailovsky 1985; Driem 1993; Bickel et al. 2010). The augments are well preserved but no longer productive. Though the original function of the $s$ augment was probably causative and that of the $t$-augment was applicative, there are now quite a few verbs which behave as augmented stems morphophonologically, but whose meanings do not even contain traces of these functions, e.g., im(-)s'sleep' or kon(-)d- 'search'. Still, there are a few fully preserved triplets such as yun- 'be there, sit' : yun-s- 'put, keep' : yuk-t- 'keep back for' and a great many pairs such as $m a-$ 'get lost' : ma-s- 'lose' or ok- 'peel' : ok-t- 'peel for'. 


\subsubsection{Causative}

Causatives are expressed periphrastically by a bare stem followed by the auxiliary mett- 'cause'. This auxiliary behaves differently from compound verbs (e.g., unlike in compounding or with benefactives, mett- does not require its host to meet a certain prosodic template, cf. Bickel et al. 2007a). The construction introduces an additional agent (the causer), marked by ERG and linked to A-AGR. The original S or A argument is marked by NOM and triggers O-AGR. As shown in (39e), all original arguments stay present and may be expressed overtly, even if this results in a tetravalent frame. ${ }^{14}$

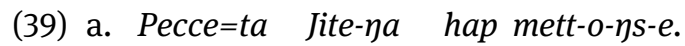

Pecce $=$ FOC Jite $=$ ERG cry cAUS-3[s]o-PRF-IND.PST[.3sA]

'Jite has made Pecce cry.'

(CLLDCh2R13S04.574)

b. U-khicin khan mai-me?-no.

3sPoss-bottom see 1nsio-CAUS-IND.NPST[.3A]

'He shows us his bottom.'

(CLLDCh1R01S01.128)

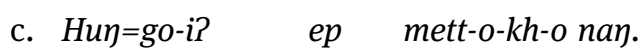

MED-NMLZ ${ }_{1}-\mathrm{LOC}_{2}$ stand CAUS-3[s]o-CON-[IMP.2SA.]3[s]o but

'Try to erect it there.'

(CLLDCh2R10S10.078)

d. Ghãsa a-chau-ce hek mett-u-ku-ci- $\eta$.

grass 1sPoss-child-ns cut CAUS-30-IND.NPST-3nso-1sA

'I let my children cut grass.'

(elicitation 2010)

e. Rame-na u-ppa u-nisa-ce phe?wa hak

Rame-ERG 3sPoss-father 3sPoss-younger.sibling-ns money send

mett-u-c-e.

CAUS-30-3nso-IND.PST[.3sA]

'Rame let his younger brothers send money to his father.'

(elicitation 2010)

\subsubsection{Compound motion verbs}

A couple of motion verbs such as kuns- 'come down' or katt- 'bring up' can be attached to other verbs. The resulting compound verb form indicates that an action

14 We note, though, that examples such as (39e) are not only highly unnatural but also awkward both to produce and to process even for native speakers. 
(expressed by the first verb) results in the location of an $\mathrm{S}$ or a $\mathrm{P} / \mathrm{T} / \mathrm{G}$ at the place indicated by the second verb:

(40) a. Gakkan u-las-a-guns-a-ce.

after.a.while 3s-come.back-PST-down-PST-d

'After a while they came back down.'

(sadstory_RM.071)

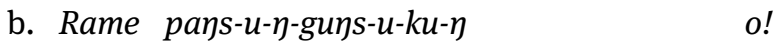

Rame send-3[s]o-1sA-down-3[s]o-IND.NPST-1sA okay

'I send down Rame, okay?'

(CLLDCh1R09S07.0984)

As shown by (40b), the valency of the compound verb is irrelevant for this process. kuns- in its independent use is an intransitive verb, but the suffix-like -guns can be used both with intransitive verbs (moving object $=S$ ) and with transitive verbs (pans- is direct object ditransitive; moving object $=\mathrm{T}$ ). - guns (and the other verbs in this class) can also add a $G$ argument to the valency of monotransitive verbs. For instance, the verb cokt- 'connect' is monotransitive, but when combined with -guns as in (41) it features an additional G:

a. Bha-mu?-ni

u-cokt-u-guns-o,

$e k$

PROX-LOC.DOWN-DIR 3[p]A-connect-3[s]P-down-[SBJV.NPST.]3[s]o one

thau le ekohoro kha?-no!

place only straight go-IND.NPST[.3ss]

'They should connect (the pipe) towards down here, (the water) just goes one way!'

(CLLDCh2R06S03.560)

Applied to ditransitives where the $G$ does not have local semantics this can result in a fourth argument, as in the following examples involving the primary object ditransitive verb apt- 'shoot (G with T)' combined with thand- 'bring down' and the double object ditransitive verb nakt- 'ask (G for T)' combined with katt- 'bring up' (> -gatt):

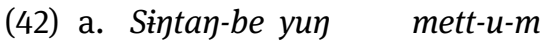

tree-LOC ${ }_{1}$ be.there cAUs-3[s]o-[sBJV.]1[p]A

kina apt-u-m-thand-u-m o!

SEQ shoot-3[s]o-1[p]A-down-3[s]o-1[p]A okay

'Let's put it on a tree and shoot it down, okay!'

(CLLDCh4R12S02.570) 
b. Kancha, huĩ bekha nakt-u-gatt-o-kh-o!

Kancha MED bag ask.for-3[s]o-up-3[s]o-con-[IMP.2sA.]3[s]o

'Kancha, ask for that bag (to be brought up)!'

(CLLDCh1R02S05.1019)

\subsubsection{Passive participle}

The suffix - mayan (-mayin for some speakers) resembles a passive participle and is therefore glossed [PASS.PTCP]. This suffix is likely to be etymologically related to the infinitive in - $m a$ and still bears some functional connections to it. Differently from the infinitive, -mayan marks events that have taken place prior to a reference point and whose results can still be seen. On the formal side, -mayan removes S/A from the frame of a verb and selects as its referent P, G of all kinds (cf. Bickel et al. 2010: 8), and all $\mathrm{T}$ except those of primary object ditransitives (pace (Bickel et al. 2010) where all $T$ arguments are claimed to be accessible for passivization, based on ambiguous data). Like all Chintang nominalizers, -mayan can be used both nominally (43a) and adnominally (43b).

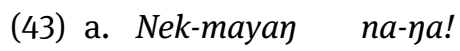

bite-PASS.PTCP refuse.to.eat-[sBJV.NPST.]1ss

'I won't eat the bitten-into one!'

(CLLDCh1R02S05.1105)

b. Hoĩ-mayin kok ca-na-nin!

mix-PASS.PTCP rice eat-[SBJV.]1SS-NEG.NPST

'I won't eat mixed rice!'

(CLLDCh2R12S01.0135)

Most of the time -maya is not used as or together with a regular argument but as in the following examples:

(44) a. Huп=go asuk-be kheir-mayin?

MED-NMLZ ${ }_{1}$ how.much-LOC ${ }_{1}$ buy-PASS.PTCP

'For how much was that bought?'

(CLLDCh4R03S03.0339)

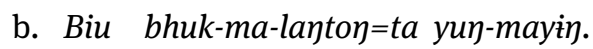

seed SOW-INF-FIN=FOC keep-PASS.PTCP

'It is kept for sowing seeds.'

(CLLDCh1R02S04.1055)

c. U-surwala anam thup-mayin $=k h a$ ?

3sPoss-trousers when sew-PASS.PTCP $=\mathrm{NMLZ}_{2}$

'When were his trousers sown?'

(CLLDCh3R02S04.780) 


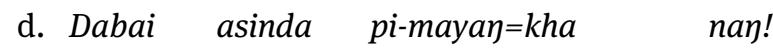
medicine yesterday give-PASS.PTCP $=\mathrm{NMLZ}_{2}$ but 'But he was given medicine yesterday!' (CLLDCh3R12S02.148)

If it weren't for rare cases such as (43) it would be possible to view the -mayan form as not nominal but verbal in nature. That would make it a true (uninflected) passive. Considering the actual situation, however, it seems better to assume that the usage in (44) is an extension of that in (43), the passive participle being used as the Rheme of the copular frame there. Under this interpretation the literal meaning of sentences such as (43b) is '(This is) something that is kept for sowing seeds'.

-mayan can be combined with all transitive verbs, but never with intransitive verbs, even if they have resultative semantics:

(45) ${ }^{\star}$ Monitar-be thai?-mayan=kha.

monitor-LOC ${ }_{1}$ appear-PASS.PTCP $=\mathrm{NMLZ}_{2}$

'It has appeared on the monitor.'

(elicitation 2011)

\subsubsection{Auxiliary alternation}

Nepali verbs are integrated into Chintang by attaching the "verbal nativizer" $-e$ to them and adding one of three auxiliaries to make a predicate out of it. The available auxiliaries are lis- 'be, become, happen', numd- 'do, perform' and mett- 'do to, do for, manipulate'.

The default is to use lis- with intransitive verbs and numd- or mett- with transitive verbs. numd- is preferred with inanimate $\mathrm{P}$ and low degrees of affection, mettwith animate $\mathrm{P}$ and high degrees of affection:

(46) Uncalis sal-be janm-e lis-a-y-kha pho.

thirty.nine year-LOC ${ }_{1}$ be.born-V.NTVZ be-PST-1sS-NMLZ 2 REP

'I was born in the year 39.'

(Ganesh_talk.69)

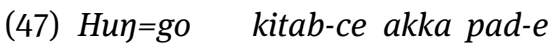

MED-NMLZ ${ }_{1}$ book-ns 1s study-V.NTVZ

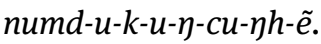

do-3[s]o-IPFV-3[s]o-1sA-3nso-1sA-IND.PST

'I was studying those books.'

(LH_BB.186-189) 
(48)
$O i, a-p p a-k o$
buru jit-e
mett-and-u-h-ẽ!
oi 1sPoss-father-GEN almost win-V.NTVZ do.to-COMPL-3[s]o-1SA-IND.PST
'Oi, I almost won against my father's!'

(CLLDCh4R02S02b.418)

These associations are, however, not fixed. Many verbs can occur with two or even all three auxiliaries:

(49) a. Gadi appi=ta rok-e lis-ad-e.

car self=FOC stop-V.NTVZ be-AWAY.ITR-IND.PST[.3ss]

'The car stopped by itself.'

(elicitation 2010)

b. Abo phaĩ-ma hi-nin, gadi rok-e num-ma now move-INF be.able-[SBJv.]NEG.NPST[.3ss] car stop-v.NTVZ do-INF koĩ hola.

must[.SBJv.NPST.3ss] maybe

'It won't move now, we'll probably have to stop the car.' (elicitation 2010)

c. Umma-ce-na gadi rok-e u-mett-e.

Maoist-ns-ERG car stop-v.NTVZ 3[p]A-do.to-IND.PST

'The Maoists stopped the car.'

(elicitation 2010)

Whereas the difference between numd- and mett- is (apart from the tendencies mentioned above) often not clear yet, the difference between these two verbs and lis-is one of valency and seems to be very similar to that observed with $\mathrm{S} / \mathrm{O}$ ambitransitives (§ 4.1.1). One possible explanation for the existence of this alternation is morphophonological. The verbal nativizer - $e$ drops preceding vowels: for instance, Nepali kamau- 'earn' becomes Chintang kam-e. One might think that this process is simply applied to the Nepali suffixes - $i$ [PASS] (e.g., rok-i- [stop-PASS] 'be stopped, stop' > Chintang rok-e, cf. above) and -au [CAUS] (e.g., bit-au- [spendCAUS] 'spend' > Chintang bit-e), too, thus levelling phonological differences that exist in the donor language but preserving the basic syntactic behavior of the borrowed forms. This would mean that examples such as in look like alternations created in Chintang but are really only made possible by processes in the donor language (with which virtually all Chintang speakers are familiar from early on).

However, Nepali causatives are even neutralized when they are not formed by a vocalic suffix. For instance, Nepali khul- 'open' (intransitive) has the transitive variant khol-; however, Chintang does not use khul-e with lis- and khol-e with numd-/mett-, but khol-e with both. What's more, numd- can even be used with verbs that cannot be causativized in Nepali, such as sıprinu 'ripen' ( ${ }^{\star}$ sıpraunu 'make ripen'): 
(50) a. Sontolon-ce sapr-e u-lis-e. orange-ns ripen-V.NTVZ 3[p]s-be-IND.NPST

'The oranges have ripened.'

(elicitation 2011)

b. Nam-ma sontoloy-ce sapr-e numd-u-c-e.

sun-ERG orange-ns ripen-V.NTVz do-30-3nso-IND.PST[.3sA]

'The sun made the oranges ripen.'

(elicitation 2011)

This makes it likely that the auxiliary alternation is a genuine innovation of Chintang with the basic aim of extending S/O ambitransitivity to loan verbs.

\section{Generalizations and conclusions}

In the preceding sections Chintang has proved to be a rich site for investigating valency and related phenomena. Up to now we have registered 15 different frames. There are three unmarked alternations and eight marked alternations of various kinds. The central topic for valency in Chintang is transitivity. This is both because the intransitive and transitive patterns are the most dominant ones and because they bear a special relationship to each other.

This becomes evident if we look at the quantitative distributions of lexical classes, defined as sets of verbs taking identical sets of frames. Transitivity is dominant in this area: the class of verbs that allows the monotransitive and the intransitive frame is the biggest verb class, with 268 out of all 663 verbs (40\%). The second biggest class, the class of verbs that is limited to intransitives, has only 131 verbs (20\%), and the next few ranks are again occupied by transitive classes: 94 direct object ditransitives (14\%), 64 primary object ditransitives (10\%), and 19 double object ditransitives (3\%). Most other classes are single-member classes, with idiosyncratic combinations of which frames are allowed by the given verb. In total there are 54 such classes. ${ }^{15}$

While transitive structures dominate in the lexicon, usage patterns suggest a tie. In the part of our corpus annotated for valency-related information, 2665 or $35 \%$ out of all 7643 verb forms use the intransitive frame and 2346 (30\%) the transitive frame. The ditransitive frames have considerably lower proportions (double object $667 / 9 \%$, direct object $620 / 8 \%$, primary object $465 / 6 \%$ ).

Transitivity becomes again more weighty when looking at the two most frequent alternations (cf. §4.1.1, §4.1.2). Out of 2702 verb forms eligible for S/A detran-

15 The distribution approximates, but doesn't match, a Zipfian cline, which is typical for lexical frequencies worldwide. 


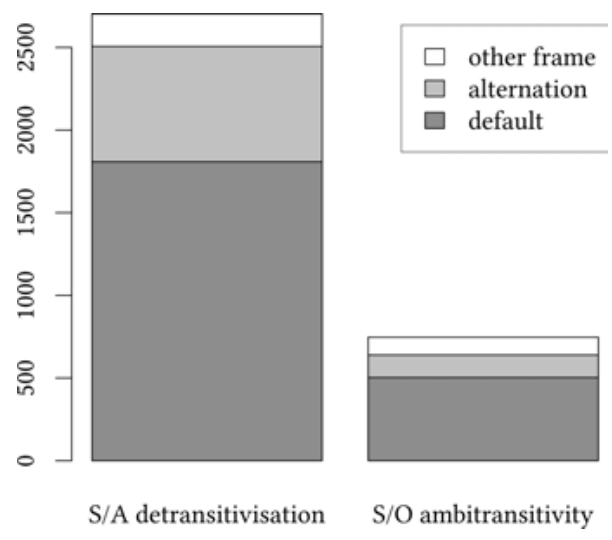

Fig. 2: Proportion of detransitivized frames in detransitivising verbs in the Chintang Language Corpus.

sitivization, $1808(67 \%)$ used the transitive frame, 698 (26\%) the detransitivized frame and 196 (7\%) other frames. Out of 746 forms of verbs attested as S/O ambitransitive, $503(67 \%)$ used the transitive frame, $136(18 \%)$ the intransitive frame and $108(14 \%)$ other frames. Thus, when generalising over all verbs the detransitivized frames are clearly not the default. Notwithstanding, the high proportion especially of S/A detransitivized frames is remarkable. Figure 2 summarizes these numbers.

We observed that the S/A-alternation - just like the S/O alternation that alternates between fully transitive and fully intransitive frames - is not lexically restricted but is fully productive and transparent. In addition, there is no clear sense of what is basic and what is derived (at least not for every single verb), i.e. the S/A and the S/O alternations are symmetrical. This suggests that in Chintang transitive verbs are defined not as verbs which must be used transitively but as verbs which can be used transitively (while intransitive verbs can be defined as those which can only be used intransitively). The flexibility of transitive verbs is also evident with regard to the remaining alternations. Almost all of them - reciprocal ambitransitivity, reflexivity and (marked) reciprocality, the passive participle, and (at least per default) benefactives - are restricted to transitive verbs. The only mechanisms that also can be applied to intransitives are the causative and compound motion verbs. There are no alternations which are only possible with intransitive verbs.

The overall picture arising from this is that of a dominating class of potentially transitive verbs that support many kinds of alternations. This suggests that flexibility is the most important property for valency in Chintang. Several flexible classes together occupying a large share of the verbal lexicon stand in contrast to a single, relatively small rigid class and a large number of small (mostly single-member) idiosyncratic classes. It is these flexible classes which are most characteristic of 
the language. While in many other languages, phenomena like ambitransitivity are lexically constrained phenomena tied to specific classes, in Chintang these patterns are fully transparent and productive. As a result, differences in transitivity are not based on strict valency classes but are a matter of degree: there are different probabilities with which a verb is used in a transitive vs. intransitive frame, and, if it is used in a transitive frame, different probabilities with which it is used in a detransitived variant.

\section{Appendix: Valency alternations on basic verbs}

Table 3 summarizes how the basic verbs collected in the Leipzig Valency Classes Project database (Hartmann et al. 2012) behave with respect to all applicable alternations described in $\S 4$. The formalism is that of the database and may in some places diverge from the formalism used above. " $r$ " ("regular") marks an alternation that is attested in the Chintang Language Corpus. "m” ("marginal”) marks alternations that are so far only attested in elicitation. “-” indicates impossible alternations. The following abbreviations are used for alternations:

$\begin{array}{ll}\text { S/O } & \text { S/O ambitransitivity } \\ \text { S/A } & \text { S/A detransitivization } \\ \text { RA } & \text { reciprocal ambitransitive } \\ \text { RC } & \text { reciprocal } \\ \text { RF } & \text { reflexive } \\ \text { B } & \text { benefactive } \\ \text { C } & \text { causative } \\ \text { P } & \text { passive participle }\end{array}$




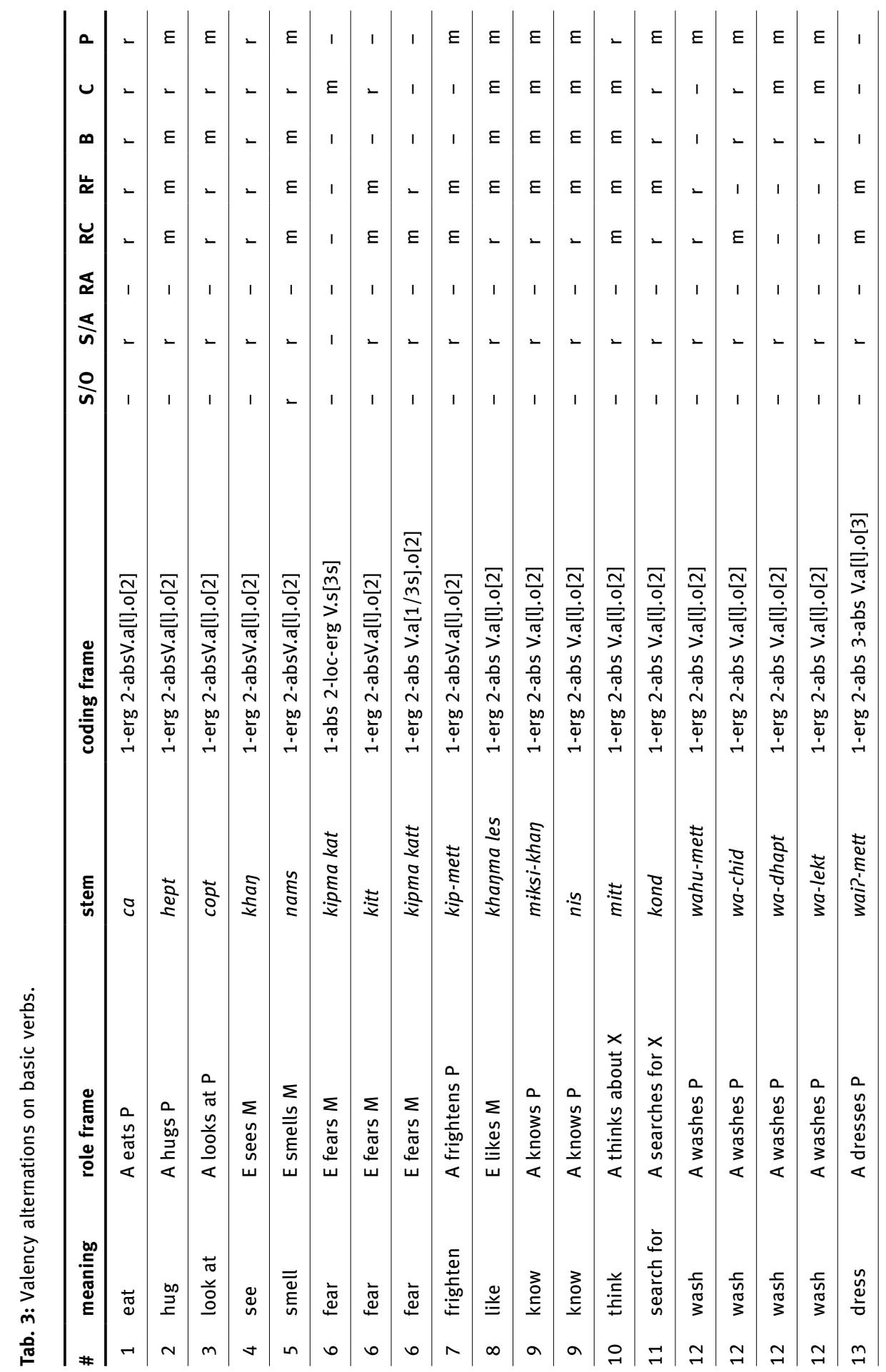




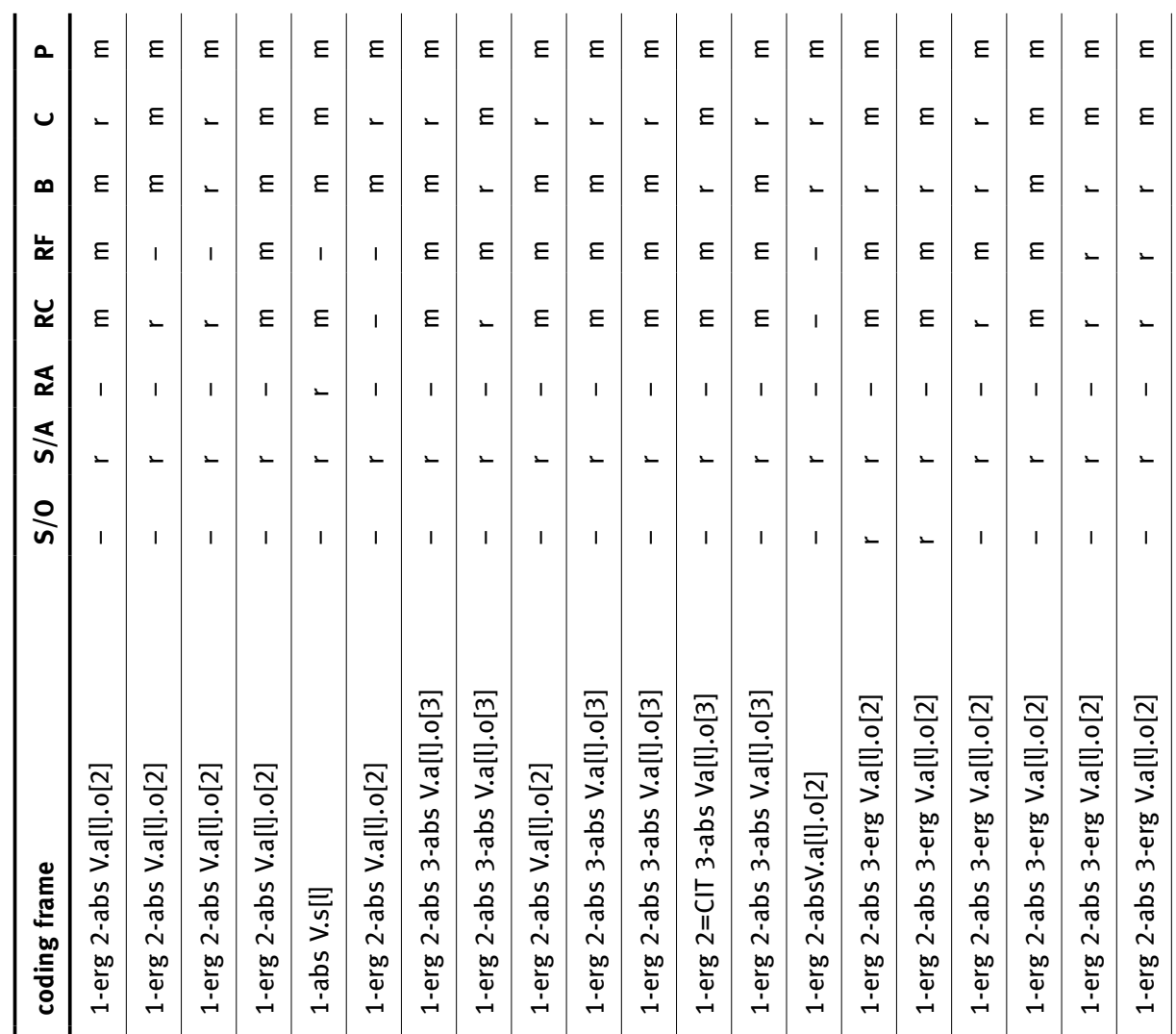

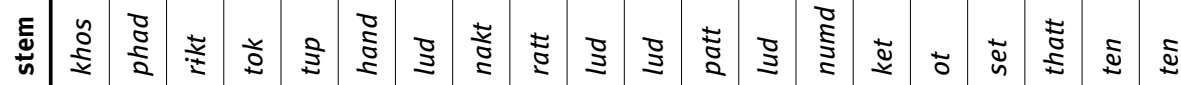

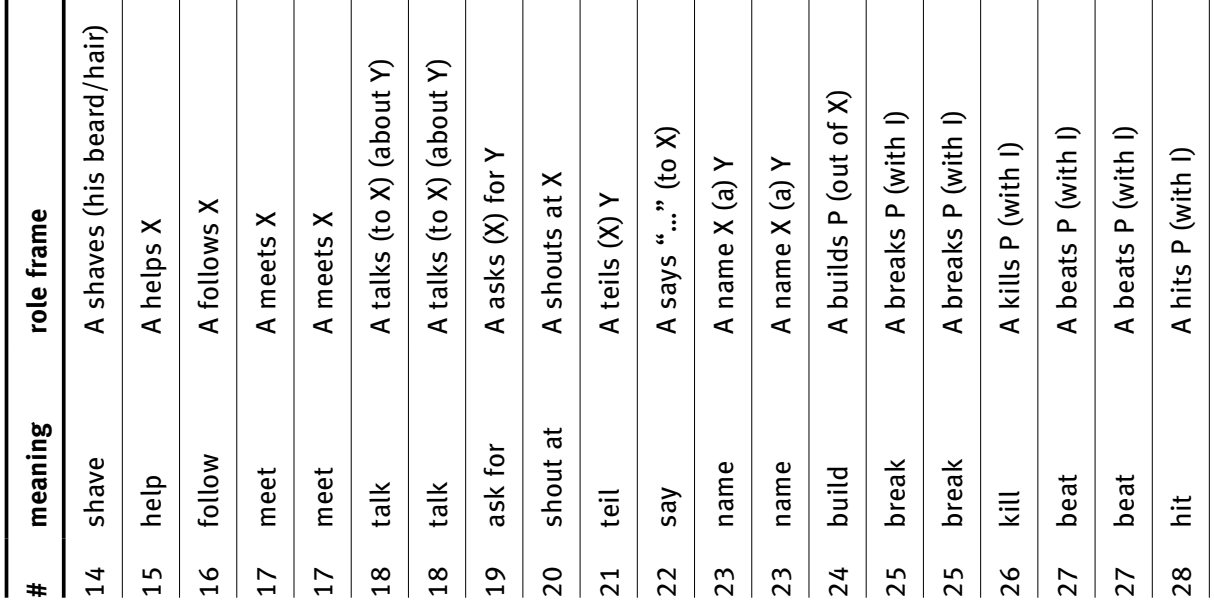



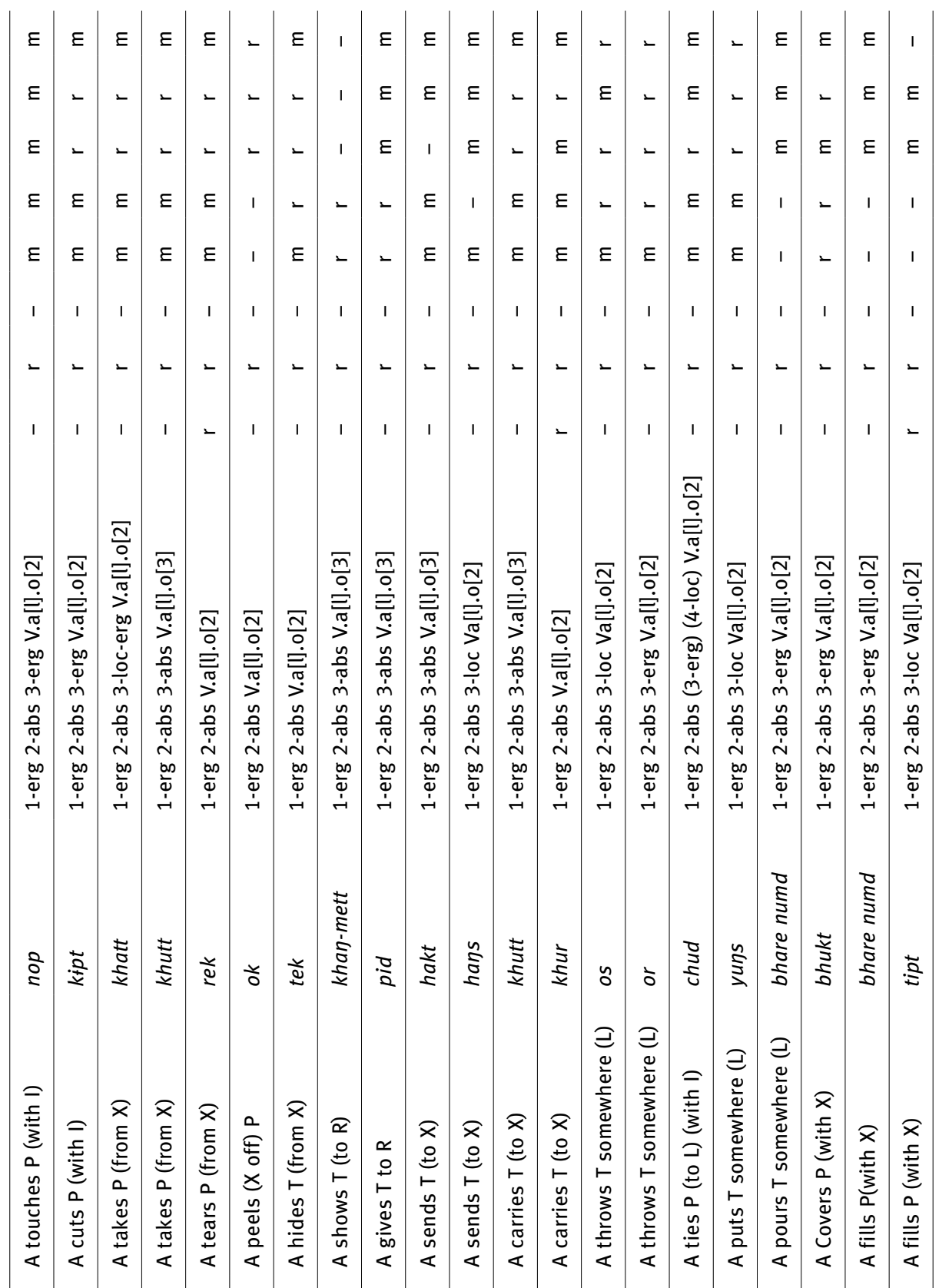

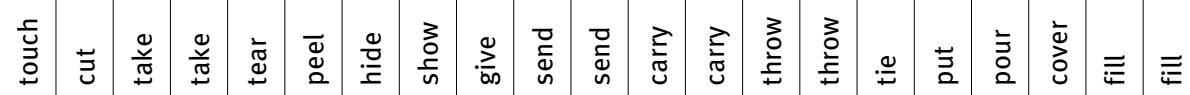

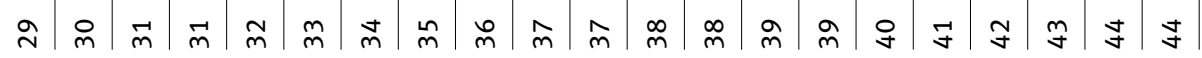




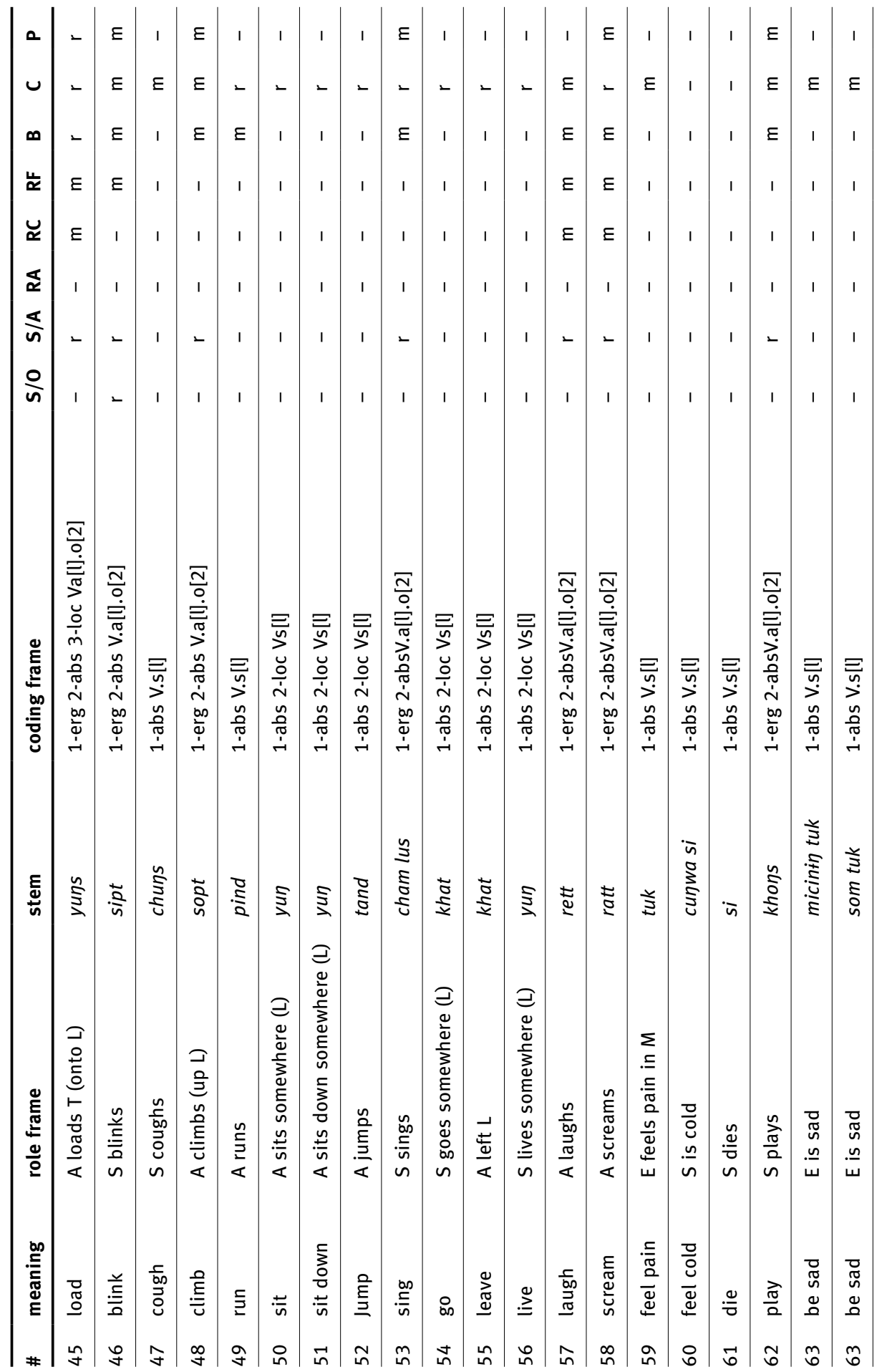




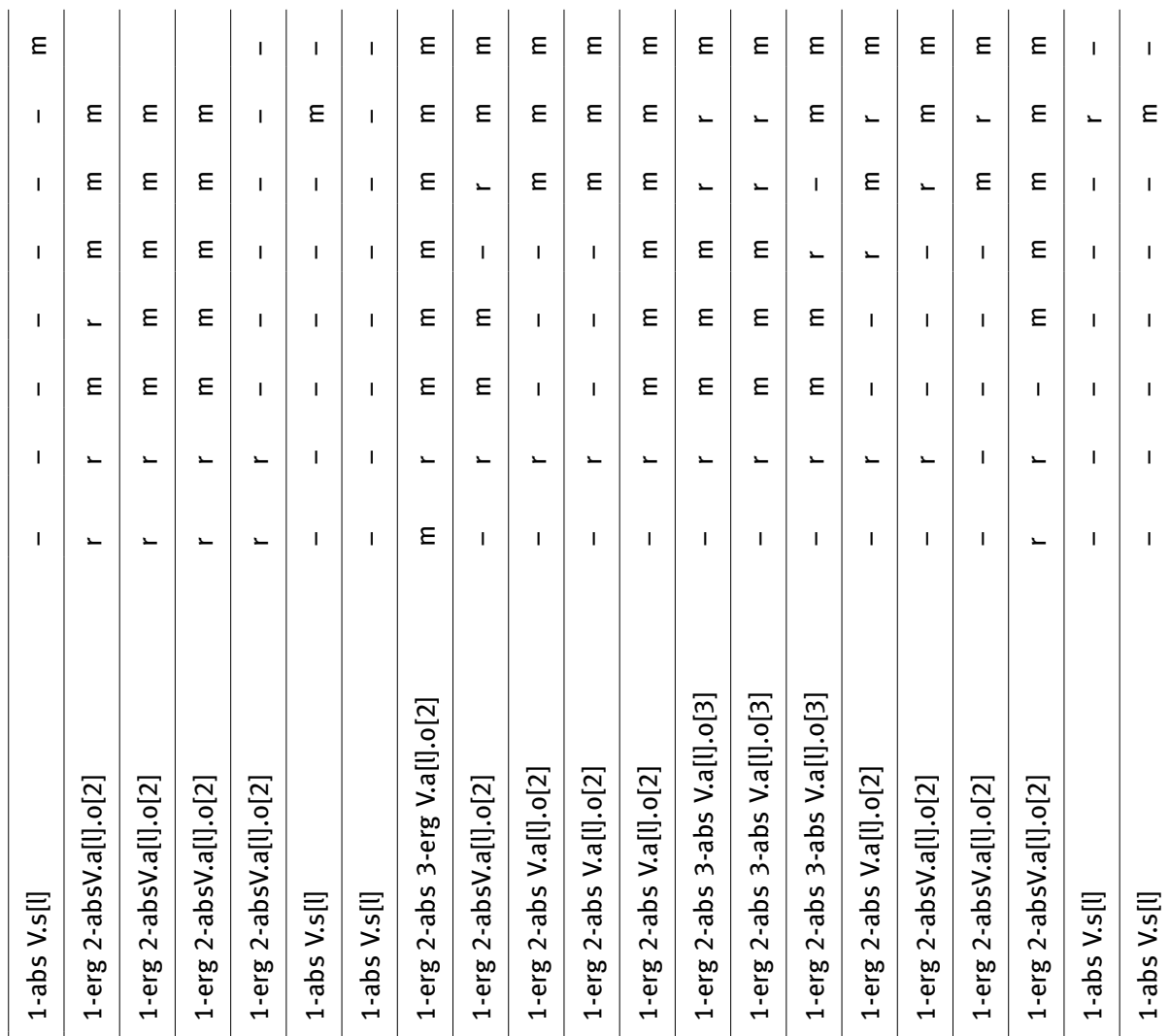

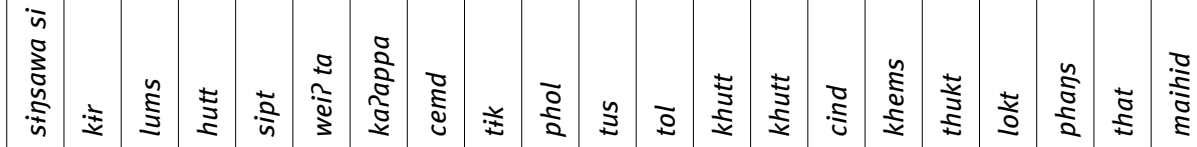

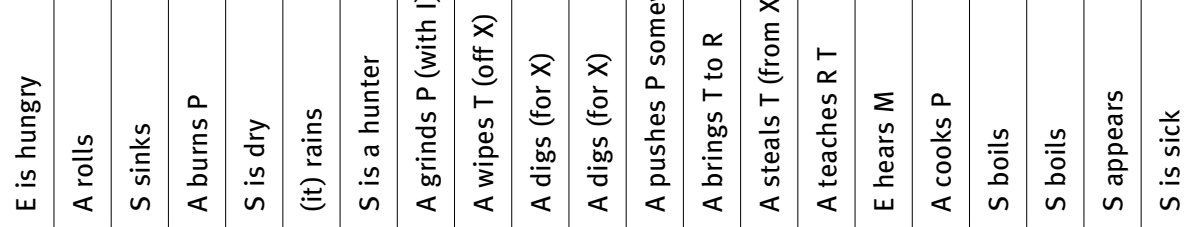

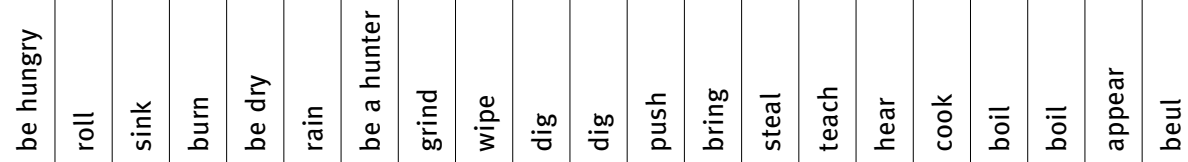

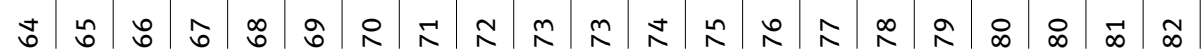




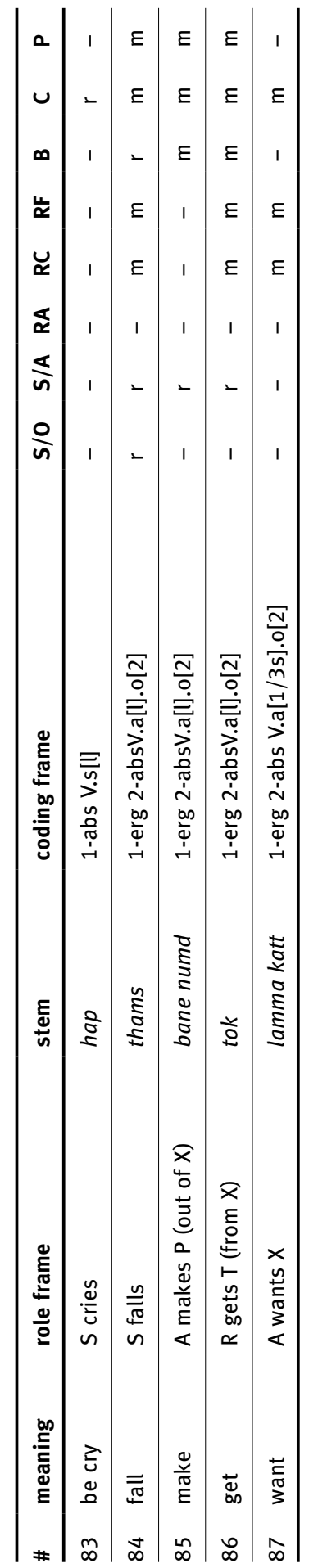




\section{Abbreviations}

\begin{tabular}{|c|c|c|c|}
\hline 1 & $1^{\text {st }}$ person & $\mathrm{i}$ & inclusive \\
\hline 2 & $2^{\text {nd }}$ person & ITR & intransitive \\
\hline 3 & $3^{\text {rd }}$ person & $\mathrm{LOC}_{1}$ & locative I (-be?) \\
\hline ACROSS & horizontal distal deixis & $\mathrm{LOC}_{2}$ & locative II (-iP) \\
\hline АCT.PTCP & active participle $(k a--p a)$ & MED & medial (huĩ) \\
\hline ADD & additive $(=y a \eta)$ & NEG & negation \\
\hline AFF & affirmative (ni) & $\mathrm{NMLZ}_{1}$ & nominalizer I $(=g o)$ \\
\hline AGR & agreement & $\mathrm{NMLZ}_{2}$ & nominalizer II $(=k h a)$ \\
\hline AUX & auxiliary & NOM & nominative \\
\hline AWAY & movement away & NPST & non-past \\
\hline A & agent & ns & non-singular $(-c e)$ \\
\hline $\mathrm{BEN}_{1}$ & benefactive I (-bid) & 0 & object $(=P / T / G+O-A G R)$ \\
\hline $\mathrm{BEN}_{2}$ & benefactive II (-chokt) & OBL & oblique \\
\hline $\mathrm{BEN}_{3}$ & enefactive III (-dhett) & OPT & optative (-ne) \\
\hline CAUS & causative (mett-) & $\mathrm{p}$ & plural \\
\hline COMPL & irreversible change (-dhend) & $P$ & patient \\
\hline CLF & (numeral) classifier & PASS.PTCP & passive participle (-mayan) \\
\hline COMPL & completive (-dhend) & POSS & possessor \\
\hline CONCS & concessive (nusayan) & PRF & perfect $(-\eta s)$ \\
\hline COND & conditional (han) & PROX & proximal $(b a)$ \\
\hline CON & 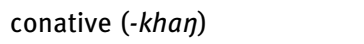 & PST & past \\
\hline CVB & converb (-saya) & PVB & preverb \\
\hline$d$ & dual & QTAG & question tag $(a \eta)$ \\
\hline DEM & demonstrative & RECP & reciprocal $(-k a)$ \\
\hline DIR & directional (-?ni) & REFL & reflexive $(-c e)$ \\
\hline DIST & distal (u-) & REP & reportative (pho) \\
\hline DOWN & vertical deixis downwards & RESTR & restrictive $(=l e)$ \\
\hline e & exclusive & $\mathrm{S}$ & singular \\
\hline EMPH & emphatic & $\mathrm{S}$ & intransitive subject \\
\hline ERG & ergative $(-\eta a)$ & SEQ & sequentializer (kina) \\
\hline EXT & extensional (-tta) & STEM & second part of bipartite stems \\
\hline FOC & focus $(=t a)$ & SBJV & subjunctive \\
\hline FIN & finalis case (-lantĩ) & SURP & surprise $(=l o)$ \\
\hline GEN & genitive $(-k o)$ & TOP & topic (na) \\
\hline G & ditransitive goal & TR & transitive \\
\hline IMP & imperative $(-a)$ & $\mathrm{T}$ & ditransitive theme \\
\hline IND & indicative & UP & vertical deixis upwards \\
\hline INF & infinitive $(-m a)$ & V.NTVZ & verbal nativizer $(-e)$ \\
\hline IPFV & imperfective (-akt) & & \\
\hline
\end{tabular}




\section{References}

Bickel, Balthasar. 1997. The possessive of experience in Belhare. In David Bradley (ed.), TibetoBurman Languages of the Himalayas, 135-155. Canberra: Pacific Linguistics (A - 86).

Bickel, Balthasar. 2003. Referential density in discourse and syntactic typology. Language 79. 708-736.

Bickel, Balthasar. 2011. Multivariate typology and field linguistics: a case study on detransitivization in Kiranti (Sino-Tibetan). In Peter K. Austin, Oliver Bond, David Nathan \& Lutz Märten (eds.), Proc. Conf. Language Documentation and Linguistic Theory 3, 3-13. London: SOAS.

Bickel, Balthasar, Goma Banjade, Martin Gaenszle, Elena Lieven, Netra Paudyal, Ichchha P. Rai, Manoj Rai, Novel K. Rai \& Sabine Stoll. 2007a. Free prefix ordering in Chintang. Language 83. 43-73.

Bickel, Balthasar, Martin Gaenszle, Arjun Rai, Prem Dhoj Rai, Shree Kumar Rai, Vishnu S. Rai \& Narayan P. Sharma (Gautam). 2007b. Two ways of suspending object agreement in Puma: between incorporation, antipassivization, and optional agreement. Himalayan Linguistics 7. 1-18.

Bickel, Balthasar, Manoj Rai, Netra Paudyal, Goma Banjade, Toya Nath Bhatta, Martin Gaenszle, Elena Lieven, Iccha Purna Rai, Novel K. Rai \& Sabine Stoll. 2010. The syntax of threeargument verbs in Chintang and Belhare (Southeastern Kiranti). In Andrej Malchukov, Martin Haspelmath \& Bernard Comrie (eds.), Studies in Ditransitive Constructions: A Comparative Handbook, 382-408. Berlin: Mouton de Gruyter.

Bickel, Balthasar, Sabine Stoll, Martin Gaenszle, Novel Kishore Rai, Elena Lieven, Goma Banjade, Toya Nath Bhatta, Netra Paudyal, Judith Pettigrew, Ichchha P. Rai \& Manoj Rai. 2011.

Audiovisual corpus of the Chintang language, including a longitudinal corpus of language acquisition by six children: ca. 9,500,000 words transcribed and translated, of which ca. 450,000 glossed, plus paradigm sets and grammar Sketches, ethnographic descriptions, photographs. DOBES Archive, http://www.mpi.nl/DOBES.

Dowty, David. 1991. Thematic proto-roles and argument selection. Language 67(3). 547-619.

Driem, George van. 1993. A Grammar of Dumi. Berlin: Mouton de Gruyter.

Du Bois, John W. 2003. Discourse and grammar. In Michael Tomasello (ed.), The New Psychology of Language, Vol. 2, 47-87. Mahwah, NJ: Erlbaum.

Ebert, Karen. 2003. Kiranti languages. In Graham Thurgood \& Randy LaPolla (eds.), The SinoTibetan Languages, chap. 31, 505-517. London/New York: Routledge.

Hartmann, Iren, Martin Haspelmath, Bradley Taylor \& Søren Wichmann. 2012. The Leipzig Valency Classes Project Database. http://www.eva.mpg.de/lingua/valency.

Malchukov, Andrej. 2008. Split intransitives, experiencer objects, and transimpersonal constructions: (re-)establishing the connection. In Mark Donohue \& Søren Wichmann (eds.), The Typology of Semantic Alignment, 76-101. Oxford: Oxford University Press.

Malchukov, Andrej, Martin Haspelmath \& Bernard Comrie. 2010. Ditransitive constructions: atypological overview. In Andrej Malchukov, Martin Haspelmath \& Bernard Comrie (eds.), Studies in Ditransitive Constructions, 1-73. Berlin: Mouton de Gruyter.

Meyer, David, Achim Zeileis \& Kurt Hornik. 2009. vcd: visualizing categorical data. R package, http: //www.R-project.org/.

Michailovsky, Boyd. 1985. Tibeto-Burman dental suffixes: evidence from Limbu. In Graham Thurgood, James A. Matisoff \& David Bradley (eds.), Linguistics oft he Sino-Tibetan Area: The State of the Art, 363-375. Canberra: Pacific Linguistics.

R Development Core Team. 2012. R: a Language and Environment for Statistical Computing. Vienna: R Foundation for Statistical Computing, http://www.r-project.org. 
Rāī, Noval Kiśor, Manoj Rāī, Netra Prasād Paudyāl, Robert Schikowski, Balthasar Bickel, Sabine Stoll, Martin Gaenszle, Judith Pettigrew, Tyko Dirksmeyer, Gomā Banjade, Icchā Purṇa Rāī, Toyā Nāth Bhatta, Sebastian Sauppe, Rikhī Māyā Rāī, Janak Kumārī Rāī, Las Kumārī Rāī, Durgā Bahädur Rāī, Ganeś Rāī, Dayārām Rāī, Durgā Bahādur Rāī, Anita Rāī, Candra Kumärī Rāī, Santi Māyā Rāī \& Ravindra Kumār Rāī. 2011. Chintang dictionary: Chintang-NepaliEnglish. DOBES Archive, http://www.mpi.nl/DOBES.

Schikowski, Robert, 2013. Object-conditioned differential marking in Chintang and Nepali: University of Zürich Ph.D. dissertation.

Stoll, Sabine, Balthasar Bickel, Elena Lieven, Goma Banjade, Toya Nath Bhatta, Martin Gaenszle, Netra P. Paudyal, Judith Pettigrew, Ichchha P. Rai, Manoj Rai \& Novel Kishore Rai. 2012. Nouns and verbs in Chintang: children's usage and surrounding adult speech. Journal of Child Language 39. 284-321.

Thurgood, Graham. 2003. A subgrouping of the Sino-Tibetan languages. In Graham Thurgood \& Randy LaPolla (eds.), The Sino-Tibetan Languages, 3-21. London/New York: Routledge. Wolfenden, Stuart N. 1929. Outlines of Tibeto-Buman Linguistic Morphology. London: Royal Asiatic Society. 
